\title{
Integrated Product, Process and Manufacturing \\ System Development for Multifunctional Micromachine Tool
}

\section{Daniel Cortés ( $\sim$ a01655708@itesm.mx)}

Instituto Tecnologico y de Estudios Superiores de Monterrey Campus Ciudad de Mexico https://orcid.org/0000-0002-8692-8066

José Ramírez

Instituto Tecnologico y de Estudios Superiores de Monterrey

Jorge Medina

Universidad de Los Andes

Arturo Molina

Instituto Tecnologico y de Estudios Superiores de Monterrey

\section{Research Article}

Keywords: Integrated Product, Process and Manufacturing System Development, Manufacturing Process, Multifunctional Micromachine Tool, Plastic Extruder, 3D Food Printer

Posted Date: January 3rd, 2022

DOI: https://doi.org/10.21203/rs.3.rs-1212182/v1

License: (1) This work is licensed under a Creative Commons Attribution 4.0 International License. Read Full License 


\section{Integrated Product, Process and Manufacturing System Development for Multifunctional Micromachine Tool}

Cortés, Daniel $^{\mathrm{a} 1^{*}}$; Ramírez, José ${ }^{\mathrm{a}}$; Medina, Jorge ${ }^{\mathrm{b}}$; Molina, Arturo ${ }^{\mathrm{a}}$.

${ }^{a}$ Escuela de Ingeniería y Ciencias, Tecnologico de Monterrey, Ciudad de México, 14380, México.

${ }^{b}$ Departamento de Ing. Mecánica, Universidad de los Andes, Bogotá, 111711, Colombia.

${ }^{1 *}$ Corresponding author at: School of Engineering and Sciences, Tecnologico de Monterrey, Mexico City, 14380, Mexico.

E-mail address: a01655708@itesm.mx. 


\section{ARTICLE INFO}

\section{ABSTRACT}

Novel practices in the formation of students are encouraged to be multidisciplinary which in fact, allows them to better understand the behaviour of systems. This skill allows them to identify existing needs that impact multiple areas, both for an organization and to complement their entrepreneurial training. In this work, there is exposed a reference framework that arose to aid in the innovative design process among the manufacturing sector, it seeks to stretch the gap between conceptualization and implementation for engineering projects. Furthermore, the formation of the learners is enriched due to the breakdown of complex systems into entities as it gathers existing knowledge and provides structure to systematize the development process, allocate problems and provide feedback. Thus, design stages are detailed, engineering stages are described, and a toolbox

\section{Introduction}

According to a Price Waterhouse Coopers article called "The World in 2050" (Price Waterhouse Coopers, 2015), most of the economic power will be transferred to the socalled Emerging Nations (E7) in the middle of the 21st century. This will result in profound transformations in their commerce, education and industry. An unprecedented increase in the consumption of goods and services will require innovative ways of producing them (Hehenberger, 2009). Innovation among the enterprises need to follow and respond faster to growing demands of novel, high quality and more personalized products as well as remain competitive in the globalized markets. Therefore, more than ever, enterprises must be aware of the challenging environment to assess and recognise their capabilities to face the competence and forecast upcoming events. According to (Koren et al., 1999), there are five major challenges to real manufacturing systems: i) increased frequency of new product introductions, ii) part upgrades for existing products, iii) product demand fluctuations, iv) changes in government regulations around the world (environmental and safety) and v) changes in process technology. Nowadays, due to the international presences that companies have, it is a common practice to find is presented to guide designers into their task. The methodology has been tested under multidisciplinary projects in different time lapses, observing a positive impact in the formation of participants, as it guarantees the inclusion of desired attributes, documentation and milestones in the scenario being developed. In this article, there are described three case studies. Findings when developing using the methodology shows a structural, documented process followed by the designers, capable of recognizing the abilities acquired and reinforced skills, documented entities corresponding to what is developed at the end of the projects and time of deployment is enhanced.

\section{Keywords}

Integrated Product, Process and Manufacturing System Development

Manufacturing Process

Multifunctional Micromachine Tool

Plastic Extruder

3D Food Printer

alliances and collaboration that allow companies to stand out from the competitors. Then, for manufacturing firms to cope with their dynamic production and aim for covering the market demands (Bainbridge \& Roco, 2006), they have been testing for different technological alternatives to improve multiple areas of the business model (Weichhart, Molina, Chen, Whitman, \& Vernadat, 2016). This takes place at different levels often involving the industryacademia duo. This synergy between entities has brought shared benefits. To the academia side, the understanding of the theory from business and how to blend a multidisciplinary view to a systematic approach, and for the industry side, the adoption of novel research technologies to the extent that allows the optimization of their productivity and expand the understanding of their environment.

Emergent technologies have aided in the manner manufacturing firms conceive, produce and bring to the physical world innovative solutions for the welfare of society (Lowe, 2005; Shamsuzzoha, Helo, \& Sandhu, 2016; Tewari, 2005).Thanks to the increased capabilities of computer hardware, the cost of some technologies has reached such an affordable point that are becoming ubiquitous. This has led to innovative solutions to embrace manufacturing challenges that require adaptable and responsive production 
lines. The adoption of multiple sensors, smart capacities, cloud computing, industrial internet of things, big data, cyber-physical systems, virtual and augmented reality, among others, have been used to collect, process and share information horizontally and vertically among the enterprises to accelerate the decision-making and monitor in real-time operations (Suginouchi, Kokuryo, \& Kaihara, 2017) to migrate into the knowledgedriven, modular and flexible manufacturing. Novel practices are intended to exchange information, automation and decision-making in real-time, as their prior objective.

Among the industrial sector that has the most benefits from the adoption of technology (Kashyap, 2019; Müller \& Voigt, 2018), manufacturing firms stand out due to complexity of the infrastructure and the multiple operations that are carried out. It is important to note that even considering previous enablers, the firm's value proposition is what enhances its position in the sector (Molina, Ponce, Miranda, \& Cortés, 2020; Porter \& Heppelmann, 2014). For instance, manufacturing firms play a fundamental role in developing countries productivity as they offer workplaces and incomes on average of $25 \%$ of their GDP (The World Bank \& OECD, 2018). Most of these firms are part of the so-called Micro, Small and Medium Enterprises (MSMEs). They present inherent advantages in the flexibility of their production lines when compared against bigger competitors, thus, can respond faster to emergent demands (Cronin, Conway, \& Walsh, 2019). Their numbers make up $97 \%$ of the manufacturing firms in some of developing countries (INEGI, 2018). All in all, there are multiple areas where MSMEs propose innovative solutions coupled with emerging technologies but end up ceasing activities in their first years of existence mostly due to the lack of structured processes to guide good manufacturing practices and improvement on the value proposition.

The collaborative work from academia with other entities along with detailed research about market tendencies and the future of jobs allowed to understand the importance that MSME will have in the medium-term future. There is a particular interest among educational institutions, the entrepreneur community, maker movement and MSME in adopting new manufacturing systems and design methodologies to cope with the upcoming challenges. These trends require manufacturing techniques that many times can only be achieved through CNC machines, but they are costly, rigid and aim at large production volumes. Also, portability is an essential characteristic since it is often necessary to constantly migrate to different workspaces. The Multifunctional Machine Tool is a type of lowcost reconfigurable machine that is positioned as an excellent hardware platform capable of supporting business development and educational environments in a small-scale production basis.

Other efforts have been focused on supporting MSMEs by generating an entrepreneur spirit in the future graduates where novel practices aim at training students to comprehensive thinking and skill development that can be translated into industrial environments to structure adamant processes that occur within manufacturing firms. Still, special attention is deserved to practice that increase competitive advantage and from this view is of paramount importance to structure the creation of products, processes and manufacturing systems, the three entities that conforms to an integrated manufacturing system (IMS).

At this point, the proposed methodology, the IPPMD: i) brings together knowledge of design, techniques, tools and procedures to aid in the creation process, ii) offers structure in multilevel and multi-size manufacturing firms, to systematize the development process since it searches for inclusion of relevant attributes, documentation and milestones, thus, allowing detection of problems in early stages and iii) promotes in its users the development of disciplinary and transversal competences by means of constant interactions between individuals and systems at all levels of the developing stages. Section 2 provides a deep insight into the proposed reference framework, offering guidelines to develop sequentially products, their manufacturing process and their productive system. Although the IPPMD supports the development of an entire manufacturing system, Section 3 only explores the manufacturing process entity that corresponds to the development of the mechanical base of the Multifunctional Micromachine Tool where details about two different modules which have been developed at Tecnologico de Monterrey are exposed. Further, in Section 4, the experience while developing using this methodology are exposed and conclusions of this work are presented.

\section{Methodology}

The reference framework followed during the realisation of this article is called Integrated Product, Process and Manufacturing System Development (IPPMD). The IPPMD arose to aid in the innovation design process among the 
manufacturing sector. IPPMD is understood as a generic model that depends on the use of engineering activities to document the process development. It gathers existing knowledge to provide structure, systematize the development of entities, allocate problems and provide feedback. It makes use of techniques, procedures, experiences and norms that apply to the manufacturing sector where it aims at being instantiated. Thanks to the feedback for developers while carrying out the stages of the framework, it is possible the recurring evaluation of tollgates that justify the progress or rejection of particular steps during its implementation.

Its effectiveness has been proved under multiple scenarios, disciplines and time lapses. Some of the applications include: i) redesign of integrated manufacturing system course of sixteen weeks, offered at Tecnologico de Monterrey for System and Industrial Engineering (ChavarríaBarrientos, Miranda, Cortés, \& Molina, 2018), ii) summer research stays of seven weeks (Cortés, Ramírez, \& Molina, 2018) from Academia Mexicana de Ciencias and Programa Delfin to strengthen research and postgraduate studies, as well as the exchange of scientific and technological production in the region of the pacific in Mexico, iii) development of technology for the Reconfigurable Micro-machine Tool 1G (Ramírez-Cadena, Miranda, Tello-Albarrán, Dávila-Ramírez, \& Molina, 2012), iv) as part of a binational project between Colombia and Mexico to conceptualize a 3D Food Printer system (Cortés, Rodríguez, et al., 2018) v) to teach rapid product development for makers and entrepreneurs in a free massive open online course (Molina, Romero, \& Ponce, 2016), vi) in collaborative networks (Cortés, ChavarríaBarrientos, et al., 2018), vii) transferring the concept to enterprises (Chavarría-Barrientos, Camarinha-Matos, \& Molina, 2017), among others. This robust framework can exceed the traditional manufacturing systems vision and be extrapolated on any object conceived as a system such as business models, communities and even cities. However, the scope in this work is related to developing Integrated Manufacturing Systems (IMS).

The IPPMD gathers entities, engineering activities, stages and viewpoints to allow the creation of an entire IMS, providing structure for those that follow the entire cycle. The basic structure of the reference model is as follows: i) Entities, which compose the system of a manufacturing firm and, ii) Stages, which are the design steps that must be followed during the creation process (Chung, Choi, Ramani, \& Patwardhan, 2005).

IMS consists of three essential entities that must be developed inside a manufacturing firm. These are: i) Products which are the main motive of a firm, ii) Manufacturing Processes to elaborate the products and which define the space, time and resources needed to be productive and the iii) Manufacturing System which establishes the parameters to be carried out during the entire cycle and contemplates both, internal and external resources of the value chain. The stages guide developers along the creation process and are four: i) Ideation of the current entity which analyses the basic scene and determines what must be done, ii) Basic Development which arises the minimal requirements to the following stages, iii) Advanced Development which faces a model of the current entity into a scenario that could be presented and, iv) Launching which analyses the behaviour of the entity in the physical world. At the end of each stage, a tollgate is achieved.

Every intersection of Entities and Stages is described in terms of their function, information, resources and organization described in (Ragatz, Handfield, \& Petersen, 2002)(Ratchev \& Hirani, 2001), to enrich the development process, there are required engineering activities (analysis, synthesis and evaluation).

Another manner to understand these interactions is that the IPPMD consists of viewpoints that conforms the IMS and, to develop the entities, it is necessary to achieve engineering activities. Thus, to develop the three entities, engineering activities must be carried out in a systemic order to assure robustness in the definition of goals. Fig. 1 depicts the reference framework where indeed stages are supported by engineering activities which consider the multiple viewpoints relevant for a manufacturing system. 


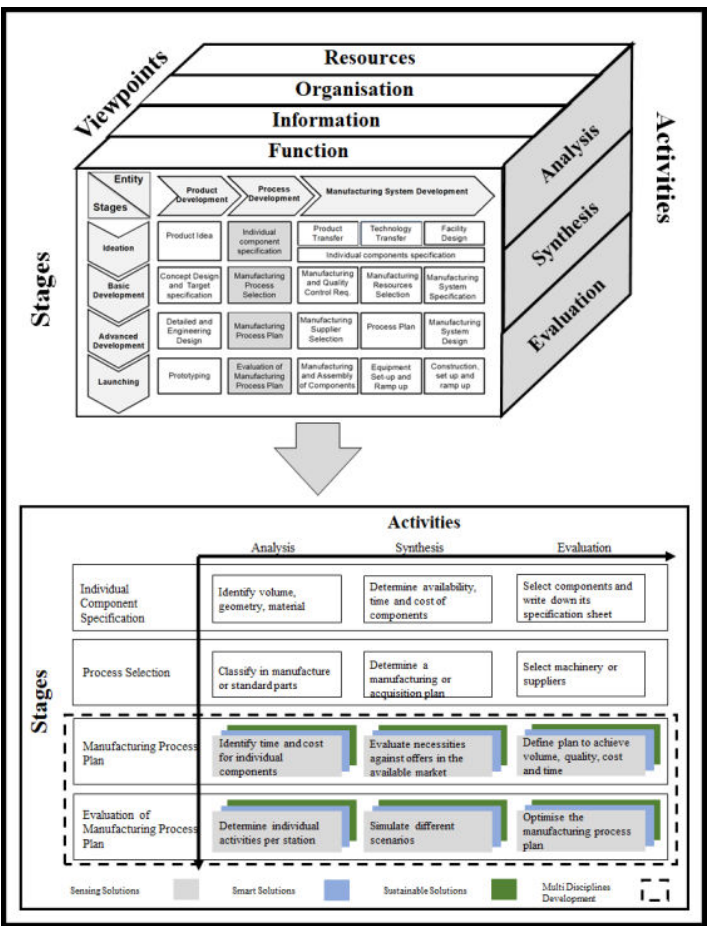

Fig. 1 Integrated Product, Process and Manufacturing System Development - Reference Framework

When combining the four ideation stages with the three entities in an Integrated Manufacturing System, the result is a partial model map to assure engineering activities along the design or redesign of the entities developed. Thus, there is an information flow that guides the structuring of engineering projects. This interaction is presented in Fig.2, where entities are broken down into the four stages and there is decision-making at the end of engineering activities per intersection.

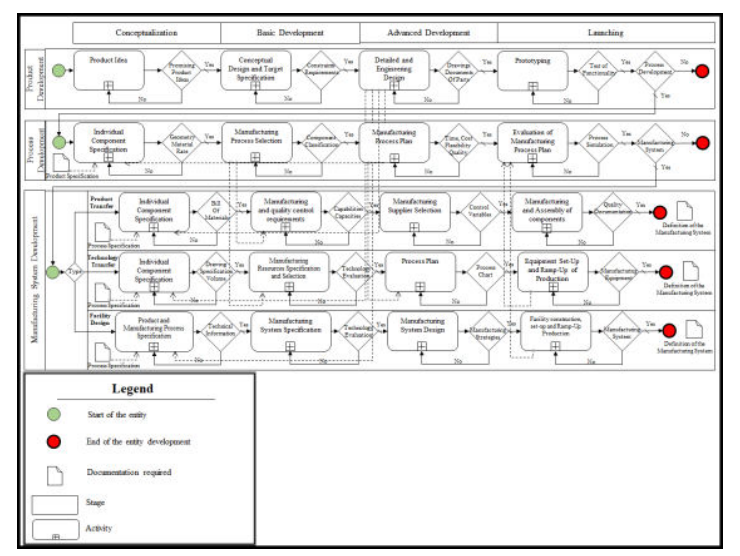

Fig. 2 Interaction between IPPMD and the Integrated Manufacturing System

Engineering activities are selected according to the entity, manufacturing sector, techniques and the scenario which allows data collection, data processing and decision-making actions. Furthermore, they are used to implement individual solutions according to analysis, synthesis and evaluation activities, this guarantees the inclusion of the attribute, documentation and milestones in the scenario being developed.

Table 1 Toolbox

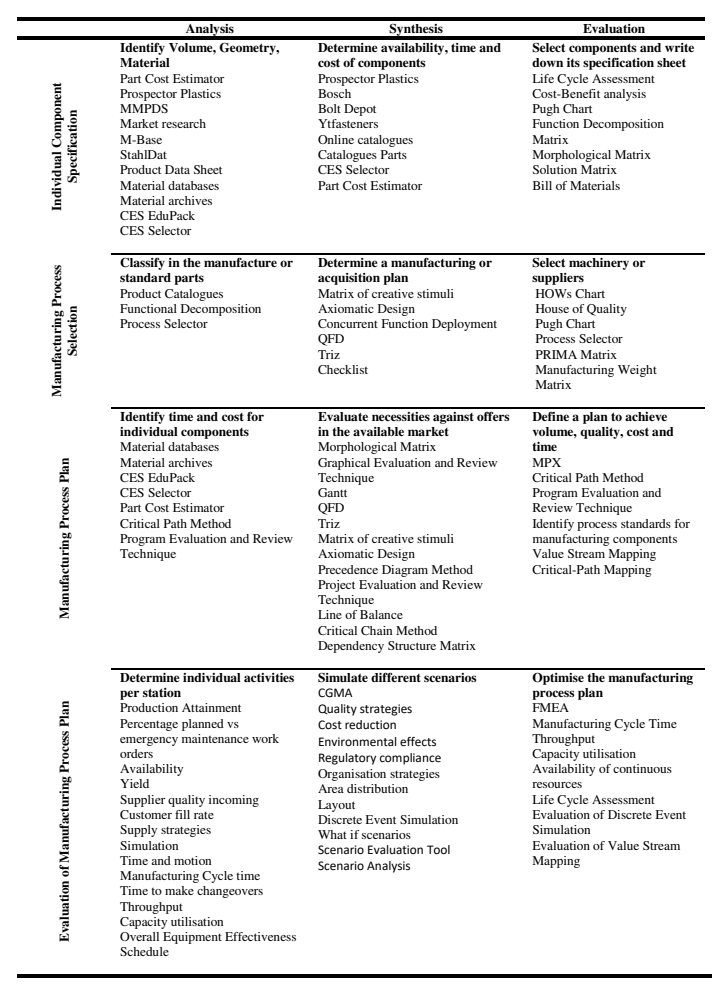

A toolbox aims at guiding the designers for gathering information related to alternatives available in the market during engineering activities. Table 1 is an example of the toolbox used during the implementation of three case studies presented in this work. It exposes different techniques applied to the development of the second entity (Manufacturing Process). It is important to remark that the toolbox provided in this article is adapted to contain different alternatives and techniques for the Manufacturing Process development in the mechanical sector. Although there is no restriction on the techniques that must be used during the deployment, different manufacturing sectors would require another specific set of techniques or restrictions to be considered in the first place. 


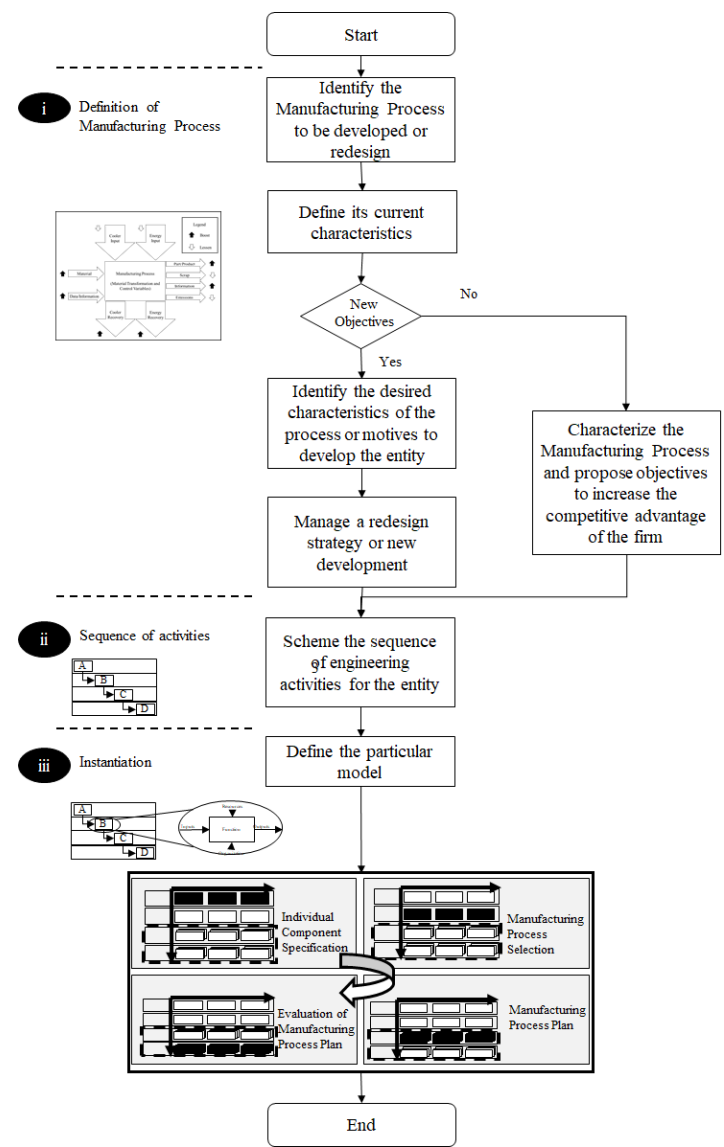

Fig. 3 Manufacturing Process Development methodology

The IPPMD aids in the development of product, process and manufacturing system entities. The Product entity has been widely studied and presented in past works related to the IPPMD. For the purpose of this article, there would be further explanation in the documentation acquired for the Manufacturing Process entity development. A brief summary of its stages is as follows: the first corresponds to the specification sheet by component that integrates the system, the consolidation of the idea to be developed. The second is the specification of the manufacturing process to continue with a detailed design of components. The third is a report of the sequence ordered to establish the manufacturing process and the components and / or services that comprise it. The fourth corresponds to the process integrated with each of the components that integrate it, functional and with tests performed. The solutions that are integrated seek to provide information along the product value chain. It consists of parts that allow sensing various aspects of the product, process and behaviour of the system in general
In order to use the IPPMD for the development of the manufacturing system entity, it must be instantiated since the beginning of the project. This practice assures the correct progress for planning as any detail can be identified by the project manager. The suggested procedure while running the IPPMD for an entity, is as follows:

i. Definition of the entity. Understanding the scope is mandatory for defining a new entity. Is it a novel or redesign of something that is available in the manufacturing firm? Does the current state of the entity fill the expectations? Is it possible to improve the entity? Is there sufficient guarantee that we are guided by the best and novel practices? Redefine the objectives or levels that the manufacturing system needs to reach, and/or propose the redesign strategy with the benefits of considering the solutions.

ii. Instantiation. First, define the set of activities according to the entity that is going to be developed. Follow the design stages for the current entity presented in the IPPMD. Last, determine which engineering activities are going to be deployed.

For the manufacturing process entity, it is important to fulfil the motives of the manufacturing firm in four categories:
a. Inputs
b. Manufacturing processes
c. Finishing processes
d. Outputs

iii. Deployment. Define the particular model for the entity and select the techniques to accomplish the objective, (if no further considerations for the sector are applicable) the toolbox proposed could be used as a guide in the manufacturing sector. Deploy the activities using the techniques selected.

The IPPMD aids in the development of product, process and manufacturing system entities, however, for the purpose of this paper, next section is going to delve in manufacturing process entity and present a summary of the product and manufacturing system, due to the dense reading that this would cause. In Fig. 3, 
there is presented the procedure followed to develop a manufacturing process entity.

\section{Application and Results}

The three case studies presented in this article are part of technology developed in the University around the patent name Reconfigurable Micro Machine Tool (RuMT) with number MX_E_2013_094998. This invention has evolved using innovative technology to increase its capabilities of production for the manufacturing sector. Novel components have been evaluated using the IPPMD reference framework in the three entities presented. Feedback and experiences from users have been considered for redesigning the RuMT. This has led to the addition of new machining features throughout using modules, allowing the process of certain materials not commonly used on tools of this scale. The module approach allows the versatility to change from one to another functionality in question of minutes, thus, creating a modular flexible machine for different purposes.

\subsection{Multifunctional Micromachine Tool}

The Multifunctional Micromachine Tool (MMT) is an open-source CNC machine capable of performing different machining operations using the same hardware arranged in different ways, it is the redesign of the RuMT. In order to obtain this extra functionality, the use of some hardware add-ons called modules is needed. It has been used as a base model to develop interesting solutions that increase the functionality beyond the classic lathe and milling operations. Some remarks are a punching module to generate stamping on some objects along with Braille marking on soft materials; as a cutter to produce cloth prototyping that need precise shapes in order to study the scalability of a proposed material to full size garment; laser engraving to perform tests on intensity and speed on finishing certain materials; a drill to perform precision marking previous to full size machining obtaining precisions close to full size $\mathrm{CNC}$ on manual work and even the addition of an extruder to perform additive manufacturing with the purpose to study design of experiments on the many parameters available to print on cold and hot beds.

The machine has become a great tool to provide a wide scope when understanding some manufacturing processes and aid students to learn the foundations when developing a product. A major advantage is the use of open source software and a standard-part approach to reduce costs and increase serviceability and life-span. Thanks to the incorporated CNC capabilities, the machine has been used by multiple engineering fields as it incorporates principles of manufacturing processes, value chain, logistics and it has been extrapolated to cover cyberphysical systems, energy consumption, ergonomics and digital twins.

The micromachine tool versatility invites to the development of newer modules to include processes not commonly found on classic numeric machines. It can support academic sector in rural areas where the CNC capabilities are limited to theory due to acquisition, maintenance or raw material cost of industrial machines. Also, its application can be extended beyond academia as has been designed considering minimum requirements to accomplish small manufacturing demands. This machine could be easily transferred to aid creators or entrepreneurs providing an affordable technology to produce low-scale CNC precision goods.

The redefinition of the MMT followed the IPPMD reference framework as explained in the following subsections.

\subsubsection{Product Development}

The stages for the first entity combined the following activities to accomplish engineering activities while developing the current stage. In Table 2 is presented the particular model for the product development of the MMT.

Product Idea. The activities that are carried out during this stage involve interaction with the possible user / client, since it allows to sketch solutions that solve the ailments or needs discovered.

Conceptual design and target specification. During this stage, weight is given to the primary needs that attack the user's problem, thus creating basic functional designs that seek to solve an existing market. In these designs it is necessary to identify the specification required by the user and verify its inclusion in the design.

Detailed engineering design. This stage involves different areas, since it integrates materials, engineering design, parts detailing, assembly simulation and hypothetical creation of assembly lines. In this stage the viability of the product is verified.

Prototyping. Finally, there are various types of prototypes. Since it is an iterative process, its development will be progressive, but initially it 
can focus on idea validation, followed by types of materials, user experience and operation.

Table 2 Particular model for the MMT - Instantiation of a Product development entity

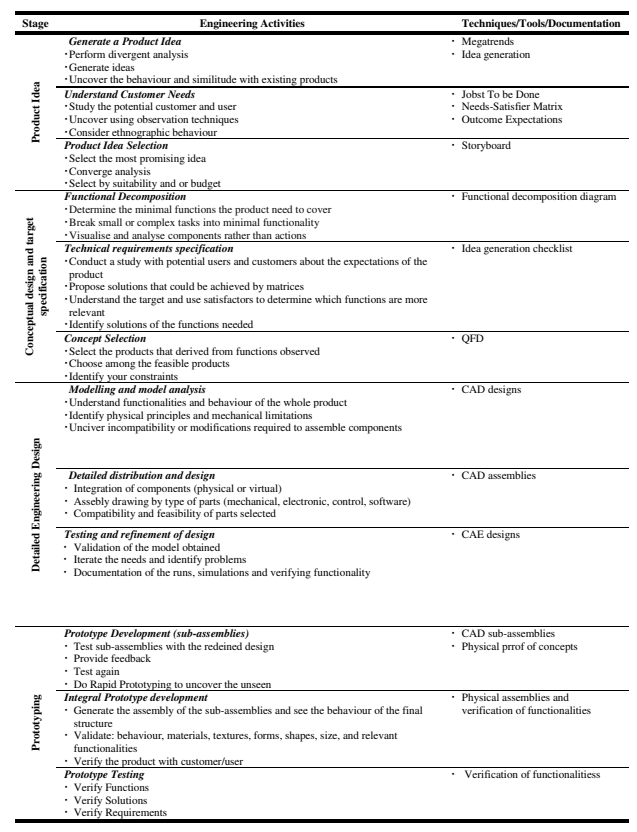

In Fig. 4, there are shown the activities and documentation of the product development entity. The MMT was carried out successfully with different modules that could be adapted in minutes, CNC capabilities and tooling are considered for the machine.

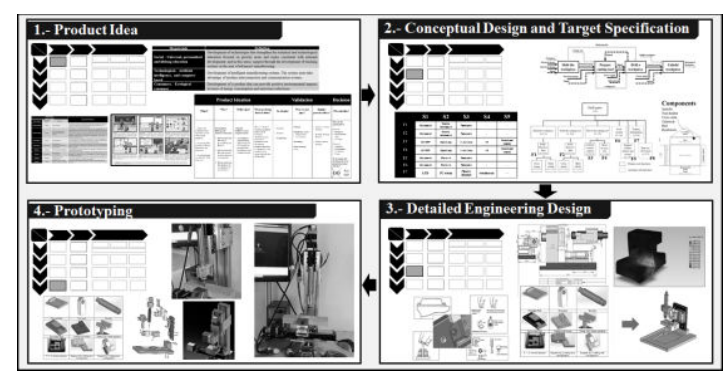

Fig. 4 Summary of the MMT-Product Development

\subsubsection{Manufacturing Process Development}

The stages for the second entity combined the following actions to accomplish engineering activities while developing the current stage. In Table 3 is presented the particular model for the process development of the MMT.
Table 3 Manufacturing Process Development. MMT

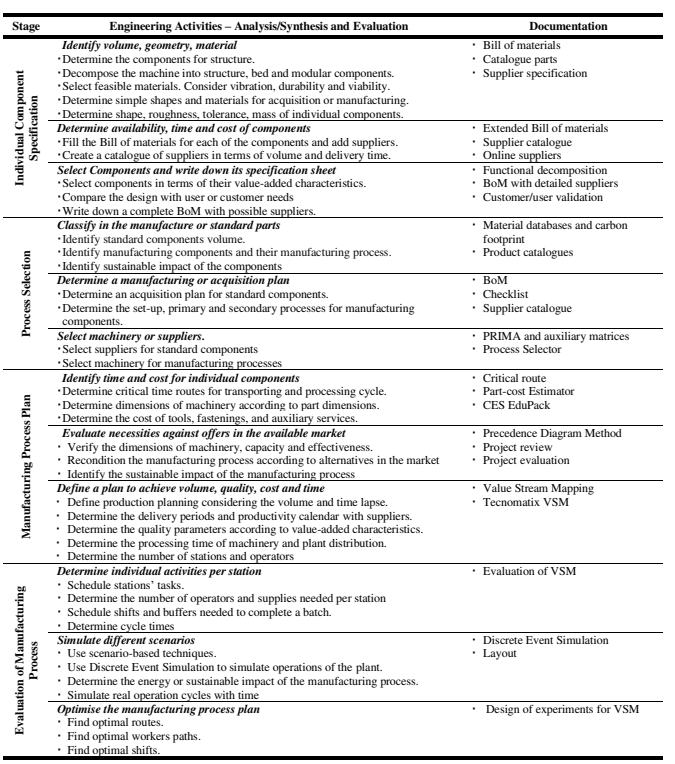

Individual Components Specification. The creation of a manufacturing process involves gathering information on the technologies available in the market, types of materials, suppliers, and the manufacture of components itself. At this stage the aforementioned details are explored.

Manufacturing Process Selection. This stage involves identifying the individual components while making a decision about the production system. The more standard parts that are included in the design, the lower the cost, but the easier it will be for competitors to reproduce the system. The more manufactured parts the product has, the higher its cost. Therefore, defining which pieces add value and difference is essential during this stage to select the mix that adds value at a reasonable cost for the market.

Manufacturing Process Plan. The plan involves the adequate selection of machines, primary and secondary parts processes, time estimation, assembly line design costs, detailing, finishing, packaging and transportation of finished parts. For a correct estimate it is necessary to define the volume that the target market will have and ensure the continuity of its delivery.

Evaluation of the Manufacturing Process

Plan. The manufacturing process plan can include different scenarios that must be refined during the evaluation, either by running physical pilots or simulating events through design strategies. In this stage, organizational objectives are prioritized to guarantee that the manufacturing process is adequate, at low cost and with a margin that allows it to be competitive in the market. The 
evaluation dictates the entry of the integrated manufacturing system.

In Fig. 5, there are shown the activities and documentation of the process development entity. It included the selection of suppliers, availability in the market, cost-benefit to the mechanical structure of the machine, analysis of cost, activities to be carried out and simulation of different scenarios to accomplish the production.

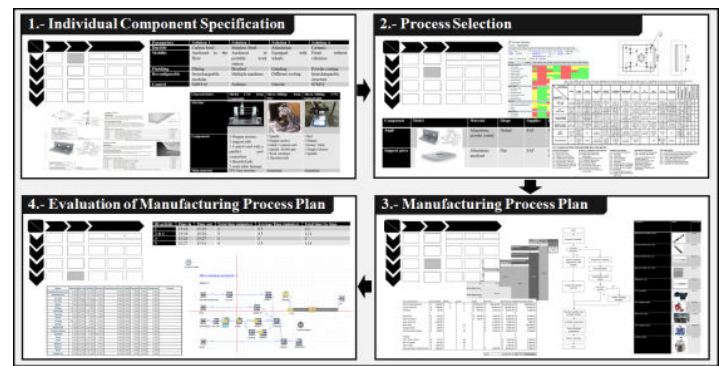

Fig. 5 Summary of the MMT-Process Development

The second entity which is the backbone of this work is presented in the following case studies, however, activities were carried out to generate a manufacturing system of the MMT. It is considered in the Manufacturing Process Plan and its evaluation the assembling of the modules in the final product according to customer requests. Plastic Extruder and 3D Food Printer Modules are detailed and conform part of the production line for the manufacturing system.

\subsubsection{Manufacturing System Development}

The stages for the third entity combined the following actions to accomplish engineering activities while developing the current stage. For the development of the manufacturing system, there are 3 main structures i) product transfer, ii) technology transfer and iii) system creation. The first of them involves the acquisition of components by suppliers and carries out activities that add value for users, such as assemblies or packaging. The second structure transfers the design of the components and takes advantage of the installed capacity of various suppliers to generate custom parts and integrate them into custom products. The third structure manufactures each of the components internally, guaranteeing the integrity of the parts and industrial protection. Its cost and industrial protection is in ascending order. In this paper, only the first one will be described. In Table 4 is presented the particular model for the manufacturing system development of the MMT.
Product Transfer. For this stage, the components must be defined based on what exists in the market and parts must be selected from various distributors that match the design. Simple manufacturing processes are generally required to condition the assembly or customization of parts.

Manufacturing and Quality Control Requirements. Referring to the tolerances, shapes, assemblies and type of information that must be verified throughout the production system. It uses industrial standards to guarantee best practices.

Process Planning. In a similar way to the manufacturing process plan, it involves the definition of costs, assembly lines, workstations, personnel, but above all delivery times with suppliers and physical space in which the activities must be carried out.

Manufacturing and Assembly of Components. It involves pilot tests or simulations of its operation to verify layout, materials, transportation, buffers, machinery, services, and reception, production and delivery times.

Table 4 Instantiation of a Manufacturing System development entity. MMT

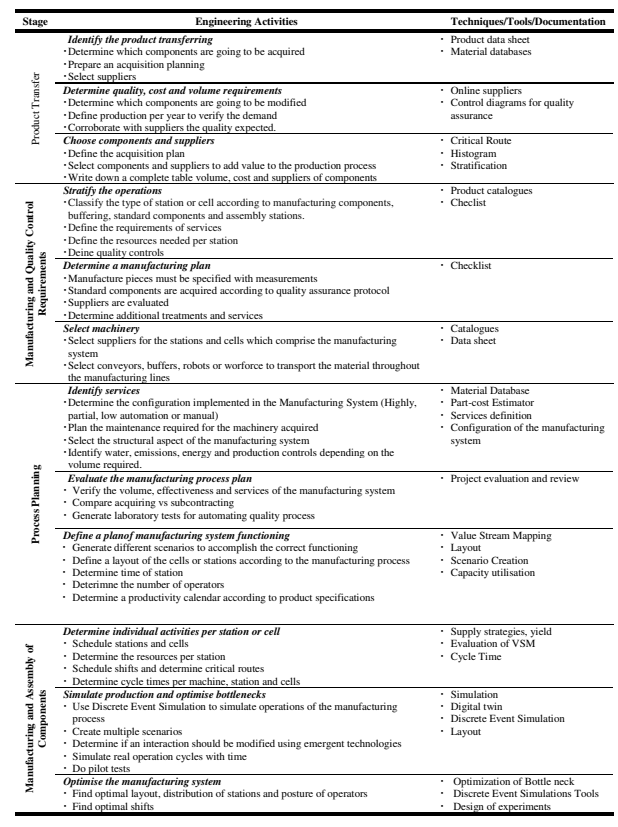

In Fig. 6, there are shown the activities and documentation of the manufacturing system development entity. It included the selection of suppliers, machinery, layout distribution and simulation for scenario creation and optimisation. It is a summary of the complete manufacturing system to produce the MMT. Nonetheless, as the manufacturing process would change according to different purposes, the modules to add 
functionalities to the machine are developed apart and their development were submitted as particular case studies.

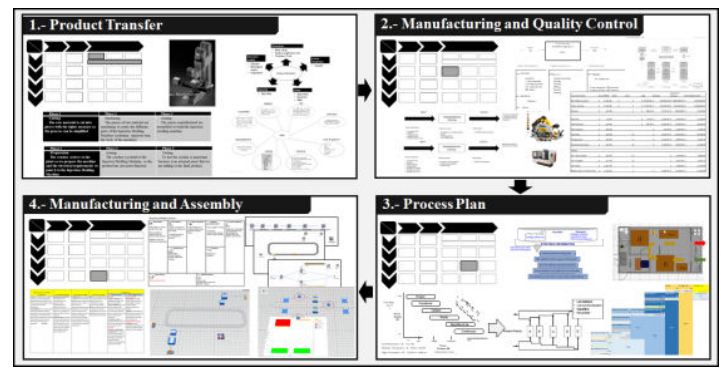

Fig. 6 Summary of the MMT-Manufacturing System Development

When developing the MMT, the responses of the designers were evaluated. The core of this project was to join the previous knowledge that students have, boost their capabilities while problem solving and structuring the process to create. About 70 per cent of the undergraduates observed considered that they had the knowledge, but not the skills to make the project. Around 80 per cent considered that the time span of four months was not enough to make the prototype nor design the manufacturing system. 100 per cent of the students developed a functional prototype of the product once they understood the methodology and structure their previous knowledge in the time span proposed. There was observed an improvement in the following skills of the participants. Critical thinking was boosted applied to problem solving, while creativity and collaboration were the two abilities students did not expect were crucial at the beginning of the project but ended up being those that were plenty used during the process. There is a perception from 90 per cent of the students that the IPPMD reference framework allows them to make any product, process and manufacturing system generated from scratch in a short time-span.

\subsection{Plastic Extruder Module}

This case study is based on an exercise for Industrial designers aiming to reuse raft and supporting material in 3D printed stuff. This is a common issue involving certain 3D printing materials such as ABS and PLA. In order to produce an even surface prior to the expected model a bed of material known as raft is extruded. This is not part of the model and is considered as waste after the process. This bed is bigger than the $3 \mathrm{D}$ model face pointing to the plate of the printer and usually its thickness varies according to the settings of the user but is usually from $1 \mathrm{~mm}$ to
$2 \mathrm{~mm}$ thick. Almost any model printed in the aforementioned materials needs rafting. Supporting material on the other hand, has the function to provide mechanical support on cantilevered details or sharp protruding edges. The fact that melted material has low viscosity increase the difficulty to print certain shapes thus the use of support is of uttermost importance. However, after the printing job, supports and rafts become waste and, in some cases, represent up to $10 \%$ of the used raw material. The degradation suffered from the thermal stress sometimes render the material unusable for 3D printer recycled reels. This waste is often thrown away whilst there are some efforts to give a second life to these materials because the plastic is suitable for other processes such as extrusion moulding. The solution explores the reconversion of this material into any plastic figures that are extrusion based.

\subsubsection{Challenges}

The premises to the development of the plastic extrusion module are: i) use of readily available raw materials and ii) the total construction parts should be reduced to the minimum. The first one helps to maintain standard parts while reducing the processes necessary to produce the model. The second aims to reduce complexity and decrease the use of joining materials while maintaining full functionality of the module. The two premises led to a set of challenges that need to be addressed by the analysis, synthesis and evaluation cycle during the product development using the IPPMD reference model. In a nutshell, the most representative are:

1. Mechanical characteristics. Materials used to construct the module must provide thermal isolation while maintaining mechanical support and strength during operations. The number of pieces should be reduced to the minimum.

2. Electric characteristics. Heating should use available voltages and control systems embedded in the base model while maintaining safety measures for the end user.

3. Modularity. Extrusion module should remain as an attachable component to the base model. Easy assembly of the subparts is wanted in order to reduce complexity thus, the rate of failure is decreased.

4. Manufacturing system. The majority of the sub-processes need to be performed within the module itself. High linearity is 
desired, when a subprocess of another family is needed it should be performed separately in order to maintain complexity at minimum.

5. Software specification. Manufacturing system should be able to perform tasks using g-code programming. A suitable strategy is needed to adapt common additive machining instructions from Computer Aided Design (CAD) to Computer Aided Manufacturing (CAM).

6. Hardware specification. Most of the parts of the module should be specified according to standard parts, this meaning custom-made elements should be reduced to the minimum.

\subsubsection{Brief summary of the final extrusion}

\section{module}

The creation of the extrusion module is no further explored in detail; however, a brief description of the final product is made in order to understand its process. As already explained in previous sections this module was developed using the IPPMD product engineering stages. The final result is shown on Fig. 7. The extrusion module is similar to any industrial extrusion system. The plastic pellets are fed into a cylindrical container that is heated, then the melted polymer is pushed through a nozzle that is connected to a mould. This way, depending on the shape of the former is possible to produce different plastic pieces in a short period of time.

Each part of the module executes a subprocess. $\mathrm{F}$ is the hopper, it has enough space to pour 50 grams of plastic pellets. In this case, $\mathrm{F}$ also function as the heater barrel, thus its construction was made using standard copper tube that is electrically isolated using fiberglass film from heater element $\mathrm{E}$. At the bottom of $\mathrm{F}$ a special gasket is used with 3 purposes: i) bond it with $\mathrm{H}$ making a leakproof seal and thermal isolation seam; ii) drive the melted plastic to the mould and iii) align the mould with the extrusion system. D is a ceramic heat shield that maintains the high temperature needed in $\mathrm{F}$ while isolating the user from the heat. In this case, melted material is not driven with an endless screw but with a metallic plunger $\mathrm{C}$ that withstands high temperature. A cage adapted from steel PTR (parts $\mathrm{G}, \mathrm{H}, \mathrm{J}$ and $\mathrm{L}$ ) is designed in such a way that allows easy mould fitting through an expulsion system (parts G, I and K). Fixture elements (parts A, B and L) are attached to the base model to provide structural rigidity and mechanical power to the system. Heater element E is driven with a temperature controller managed by the software. The result of the synergy between all the elements provide the functionality to perform an extrusion process on the base model.

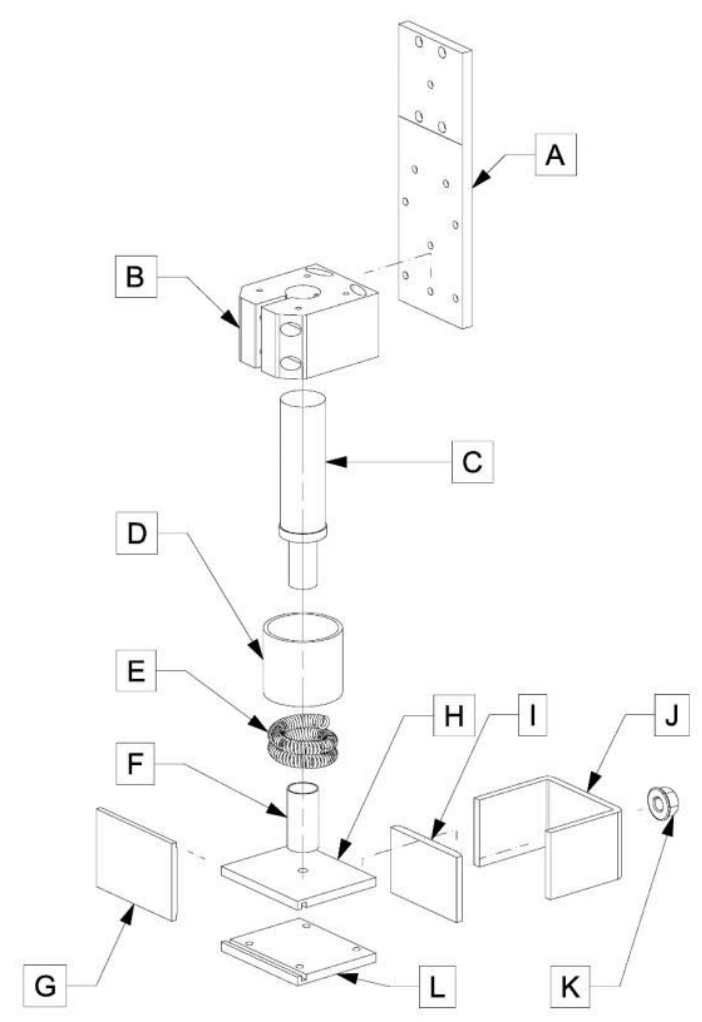

Fig. 7 Plastic extrusion module exploded view

\subsubsection{Manufacturing Process analysis of the}

\section{plastic extrusion module}

Manufacturing planning requires the integration of multidisciplinary work and skills to design an optimal process with available resources in the market. However, from all possible paths, some guidelines are needed to get the best solution possible while maintaining sustainability in all the axes. Thus, this methodology was selected to guide the realisation of stages in the designing process of the extrusion module. Following the methodology exposed in Fig. 6 and aided by the toolbox presented in Table 1, the Manufacturing Process that corresponds to the second entity of the IPPMD was developed. According to the proposed roadmap for the development of the plastic extrusion module, the following activities were done: i) Definition of Manufacturing Process, ii) Instantiation and iii) Deployment. 


\section{i) Definition of Manufacturing Process.}

As previously mentioned in the methodology approach, this is a general manufacturing process enhancement case, thus, analysis mainly aims to the machine tools that processes the module. It is of high importance to determine along the development if all the parts are to be produced infacility or some outsourcing will be needed. If there are activities that are held outside the firm a brief analysis will take place, some data can be obtained from delivery point to plant processing. This implies the correct selection of machines, tools and strategies to reduce the amount of waste during the manufacturing process. In order to remain competitive on the long term, planning must consider higher upcoming environmental restrictions.

\section{ii) Instantiation.}

The sequence of activities considers engineering activities (analysis, synthesis and evaluation) coupled with tollgates are used to guide designers into the definition of the Manufacturing Process. Table 5 summarizes the relationship between instantiation stage and the tools needed to achieve the process plan.

Table 5 Manufacturing Process Development. Extrusion Module

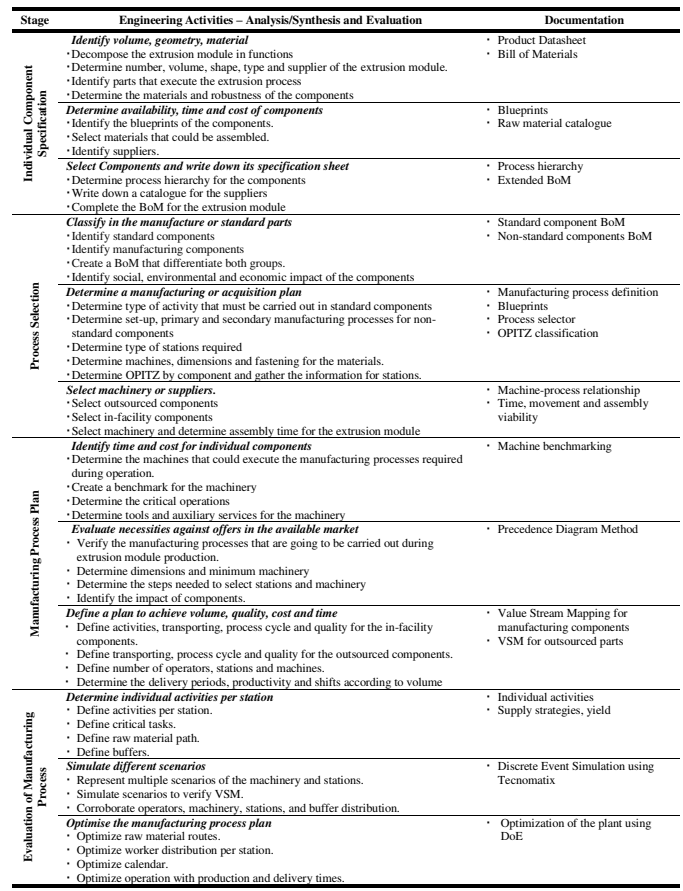

\section{iii) Deployment.}

In the following section are described all individual activities carried away during the development of the Manufacturing Process of the module. Process is demonstrated analysing the model's development four stages: i) Individual Component Specification ii) Process Selection, iii) Manufacturing Process Plan and iv) Evaluation of Manufacturing Process.

\subsubsection{Individual Component Specification}

At this section, individual parts of the module are analysed to assess the raw material needed to produce them. For this module, most of the specifications are already available thanks to the detailed prototyping achieved during product development. Material, sizes and tolerances are in datasheets reducing time to do the instantiation in this section. Most of the work is for defining raw material to produce the parts.

\section{Analysis: Identify volume, geometry and material}

The extrusion module has been previously designed according to the product development stage. At this point detailed information is available in order to analyse process planning. Some insight on the requirements were analysed as the use of standard parts to develop a highly functional prototype. Detailed specs on the datasheet is provided for every part of the module (See Table 6). Additional information of the availability of OEM components were considered. Material was previously selected and analysed to withstand temperature and strain when working.

Table 6. Datasheet catalogue for the extrusion module

\begin{tabular}{|c|c|c|c|c|c|}
\hline Part & Name & Plane & Material & Machining & OEM \\
\hline A & Motor base & & Aluminium & Yes & Yes \\
\hline B & Plunger holder & 13 & Plastic & No & No \\
\hline c & Plunger & & Steel & Yes & Yes \\
\hline D & Ceramic shield & 5 & Ceramic & No & Yes \\
\hline$E$ & Heating element & 3 & Steel & No & Yes \\
\hline $\mathrm{F}$ & Hopper & & Copper & Yes & Yes \\
\hline G & Mould Lid & & Steel & Yes & Yes \\
\hline $\mathrm{H}$ & Mould case cover & & Steel & Yes & Yes \\
\hline 1 & Eject element & & Steel & Yes & Yes \\
\hline J & Mould case & & Steel & Yes & Yes \\
\hline $\mathrm{k}$ & Eject screw & $\cdot 1$ & Steel & No & Yes \\
\hline L & Mould case base & - 47 & Steel & Yes & Yes \\
\hline
\end{tabular}

According to datasheets, most of the process to produce final part are reduced to minimum as very little customization is needed. Standard tools 
provide size and tolerances within the range of the final part. Standard raw material is treated in next section as there are many baseline solutions.

\section{Synthesis: Determine availability, time and cost of raw material}

Availability of components are consulted with local and foreigner providers. Among catalogues present at the realisation of this exercise, standard raw material is selected to provide final part close to raw material specs, thus, very little machining is needed. The majority of structural material can be purchased locally, catalogue number is not provided by the manufacturer, only reported size is necessary for querying purposes (See Table 7). Standard raw material is always available, and no shortage is reported. Is also important to note that the former has been consulted and it will remain in the catalogue for a long time because it is an industrial standard.

Table 7 Raw material catalogue for extrusion module

\begin{tabular}{c|lcccc}
\hline Part & Name & Raw material size & Presentation & Make & Number \\
\hline A & Motor base & $2 \times 1 / 4$ in bar & $6 \mathrm{~m} \mathrm{bar}$ & MIPSA & - \\
B & Plunger holder & Custom made & piece & - & - \\
C & Plunger & 1 in rod & $6 \mathrm{~m} \mathrm{rod}$ & FORTACERO & - \\
D & Ceramic shield & Custom made & piece & - & - \\
E & Heating element & $20 \mathrm{~cm}$ & piece & Indiamart & $100 \mathrm{wt}$ \\
F & Hopper & $5 / 8$ in & $6 \mathrm{~m}$ tube & Nacobre & - \\
G & Mould Lid & $2 \times 1 / 8$ in & $6 \mathrm{~m} \mathrm{bar}$ & FORTACERO & - \\
H & Mould case cover & $2 \times 1 / 8$ in & $6 \mathrm{~m} \mathrm{bar}$ & FORTACERO & - \\
I & Eject element & $2 \times 1 / 8$ in & $6 \mathrm{mbar}$ & FORTACERO & - \\
J & Mould case & $2 \times 2$ in PR & $6 \mathrm{~m} \mathrm{bar}$ & FORTACERO & - \\
K & Eject screw & M8 screw & piece & BoltDepot & 13358 \\
L & Mould case base & $2 \times 1 / 8$ in & $6 \mathrm{~m}$ bar & FORTACERO & - \\
\hline
\end{tabular}

After considering available material options, it is possible to make calculations about raw material yield as some bars and rods are very large and several parts can be obtained from them. According to projected production, estimation cost is visualised in Table 8 .

Table 8 Raw material catalogue cost for extrusion module

\begin{tabular}{c|lccccrr}
\hline Part & $\begin{array}{c}\text { Raw material } \\
\text { size }\end{array}$ & Presentation & $\begin{array}{c}\text { Target } \\
\text { Volume }\end{array}$ & $\begin{array}{c}\text { Yield } \\
\text { pet } \\
\text { pieces }\end{array}$ & $\begin{array}{r}\text { Unitary cost } \\
\text { (USD) }\end{array}$ & $\begin{array}{r}\text { Subtotal } \\
\text { (USD) }\end{array}$ \\
\hline A & $2 \times 1 / 4$ in bar & $6 \mathrm{~m}$ bar & 100 & $40: 1$ & 3 & $\$ 24$ & $\$ 72$ \\
B & Custom made & piece & 100 & - & 100 & $\$ 5$ & $\$ 500$ \\
C & 1 in rod & $6 \mathrm{~m}$ rod & 100 & $48: 1$ & 3 & $\$ 15$ & $\$ 45$ \\
D & Custom made & piece & 100 & - & 100 & $\$ 2$ & $\$ 200$ \\
E & $20 \mathrm{~cm}$ & piece & 100 & - & 100 & $\$ 4$ & $\$ 400$ \\
F & $5 / 8$ in & $6 \mathrm{~m}$ tube & 100 & $113: 1$ & 1 & $\$ 45$ & $\$ 45$ \\
G & $2 \times 1 / 8$ in & $6 \mathrm{~m}$ bar & 100 & $113: 1$ & 1 & $\$ 15$ & $\$ 15$ \\
H & $2 \times 1 / 8$ in & $6 \mathrm{~m}$ bar & 100 & $113: 1$ & 1 & $\$ 15$ & $\$ 15$ \\
I & $2 \times 1 / 8$ in & $6 \mathrm{~m}$ bar & 100 & $113: 1$ & 1 & $\$ 15$ & $\$ 15$ \\
J & $2 \times 2$ in PTR & $6 \mathrm{~m}$ bar & 100 & $113: 1$ & 1 & $\$ 23$ & $\$ 23$ \\
K & M8 screw & piece & 100 & - & 100 & $\$ 0.5$ & $\$ 50$ \\
L & $2 \times 1 / 8$ in & $6 \mathrm{~m}$ bar & 100 & $113: 1$ & 1 & $\$ 15$ & $\$ 15$ \\
\hline
\end{tabular}

\footnotetext{
Evaluation: Write down process specification sheet

Datasheet provided an insight about machining operations for each part, however, when combined with raw material specs the complete set of necessary steps is noticeable. This provides the
}

information needed for the next stage. In Table 9, the core hierarchy machining operations are shown in order to plan the machines needed to operate the plant.

Table 9 Process hierarchy for the extrusion module parts

\begin{tabular}{clccccc}
\hline Part & Name & Process 1 & Process 2 & Process 3 & Process 4 & Process 5 \\
\hline A & Motor base & Cutting & Drilling & Tapping & Deburring & - \\
B & Plunger holder & Tapping & - & - & - & - \\
C & Plunger & Cutting & Deburring & - & - & - \\
D & Ceramic shield & - & - & - & - & - \\
E & Heating element & - & - & - & - & - \\
F & Hopper & Cutting & Deburring & - & - & - \\
G & Mould Lid & Cutting & Milling & Deburring & - & - \\
H & Mould case cover & Cutting & Drilling & Deburring & Welding & - \\
I & jeect element & Cutting & Chamfering & Deburring & - & - \\
J & Mould case & Cutting & Deburring & Welding & - & - \\
K & Eject screw & - & - & - \\
L & Mould case base & Cutting & Milling & Drilling & Deburring & Welding \\
\hline
\end{tabular}

\subsubsection{Process Selection}

At this part a few considerations take place to provide a baseline for calculations. Until now it was possible to understand the machining process to obtain the parts necessary to assemble the module, however, from this section it is essential to provide target volumes of production. The baseline for the rest of the steps is a production of 100 modules a month, most of the manufacturing is made inside the facility, however some outsourcing is expected.

There are many solutions to a given problem, in this case different machines and machining processes can have similar results however, time and precision will force to choose between several available solutions. For this section is imperative the use of process selection tools in order to do faster calculations. At this level an analysis of each part must be made but in order to summarize this exercise, just a couple of parts will be described.

\section{Analysis: Classify in the manufacture or standard parts}

Most of the raw material can be obtained from supplier catalogues. However, according to table 14 , just four of them need small adjustments or don't need machining at all. Tables 10 and 11 show the classification of the parts, depending on the former, the operations needed to obtain the final result will vary. Most of them will only need lathe, mill and drilling operations to some extent, however, specific subprocess will be analysed on further steps. 
Table 10 Standard Components of the extrusion module

\begin{tabular}{clccccc}
\hline Part & Model & Dimensions & Shape & Material & Supplier & ID \\
\hline $\mathrm{E}$ & $\begin{array}{l}\text { Heating } \\
\text { element }\end{array}$ & & Spiral & Steel & Indiamart & $100 \mathrm{wt}$ \\
$\mathrm{K}$ & Eject screw & Complex & Steel & BoltDepot & 13358 \\
& & & & & & \\
\hline
\end{tabular}

Table 11 Non-Standard Components of the extrusion module

\begin{tabular}{|c|c|c|c|c|c|c|}
\hline Part & Model & Dimensions & Shape & Material & Supplier & ID \\
\hline B & Plunger holder & $\cdots$ & Complex & Plastic & Custom & - \\
\hline D & Ceramic shield & 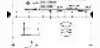 & Round & Ceramic & Custom & - \\
\hline A & Motor base & & Prismatic & Aluminium & MIPSA & - \\
\hline $\mathrm{F}$ & Hopper & $\because$ & Round & Copper & Nacobre & - \\
\hline G & Mould Lid & & Prismatic & Steel & FORTACERO & - \\
\hline$H$ & $\begin{array}{l}\text { Mould case } \\
\text { cover }\end{array}$ & & Prismatic & Steel & FORTACERO & - \\
\hline 1 & Eject element & & Prismatic & Steel & FORTACERO & - \\
\hline J & Mould case & & Complex & Steel & FORTACERO & - \\
\hline L & $\begin{array}{l}\text { Mould case } \\
\text { base }\end{array}$ & & Prismatic & Steel & FORTACERO & \\
\hline
\end{tabular}

Synthesis: Determine a manufacturing or acquisition plan

Manufacturing can be classified at this point in two axes: i) processes needed to produce the individual parts and ii) processes to consolidate and assemble the module. Both need to be explored in detail to determine an action plan. A deep insight on this will provide a baseline to project if in-facility manufacturing is costeffective for every part or if is necessary to do some outsourcing to reduce costs. Table 12 summarizes the steps needed to consolidate the module.

Table 12 Manufacturing processes for the extrusion module

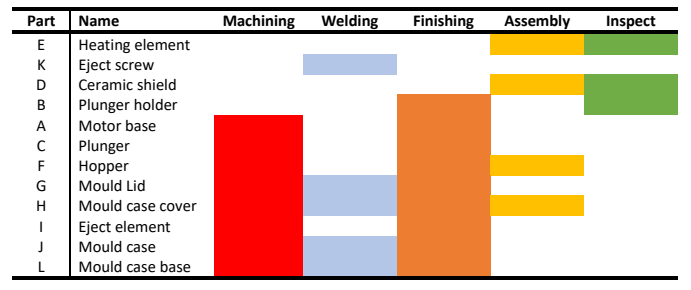

Some of the manufacturing processes can be processed on the same machine reducing acquisition cost, however a detailed evaluation needs to be done to determine the machine tools needed or the acquisition plan. For this brief example, just processes needed to produce the individual parts are covered and a couple of parts are displayed. Two approaches are covered.

There are some available databases that help to determine the best process to produce certain pieces. It depends on data as the shape, tolerance and lead time to say a few (See Table 13). This gives a rough estimation and is not always reliable as it not considers subprocess needed get the result. In this example the motor base is analysed using a process selector (see Fig. 8).

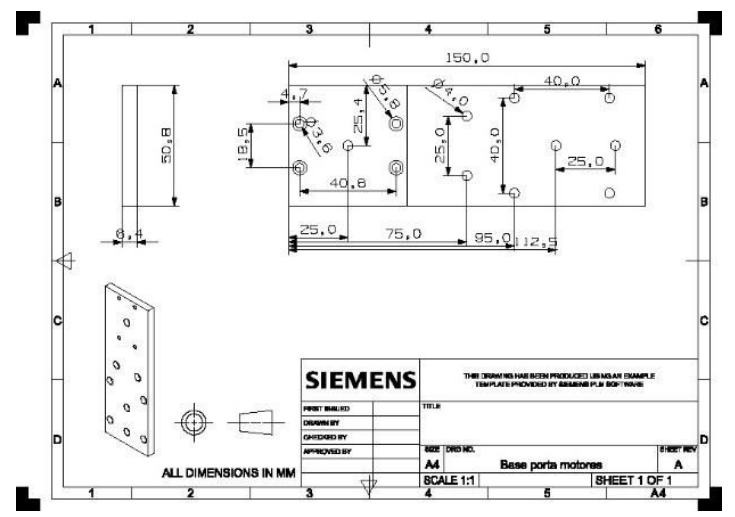

Fig. 8 Part A, the motor base (all dimensions are in $\mathrm{mm})$

- Material: Aluminium

- The volume of production: 100 per month

- Tolerance (+-0.05)

- Surface roughness: $0.50 \mathrm{um}$

- Mass: $0.130 \mathrm{~kg}$ 
Table 13 Projected process for part A using a process selector tool

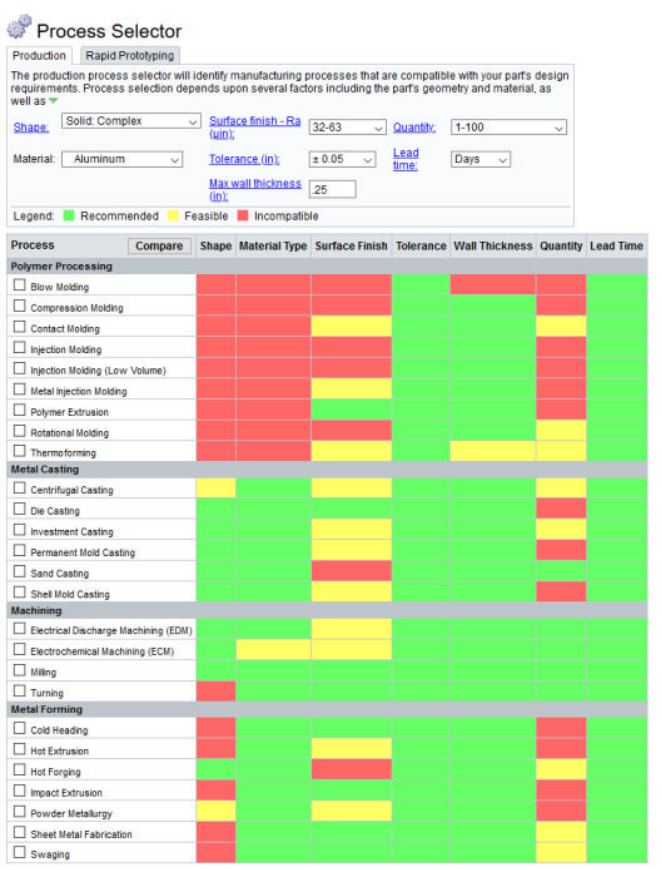

Is clear that best selection is a milling machine, but when it is considered that raw material is close to the size, the proper operation is just cutting and then drilling. This is a valuable tool for non-complex pieces like $\mathrm{D}, \mathrm{C}$ or even $\mathrm{F}$.

OPITZ is used as another approach to determine the manufacturing subprocesses to machine the extrusion plunger (see Fig. 9). At first glance is evident that a lathe is the preferred machine to produce it however, tools can increase production costs as there are operation that can only be made using special inserts. For this, OPITZ serves as a great tool to determine the inserts that will be needed to cut the plunger (see Table 14).

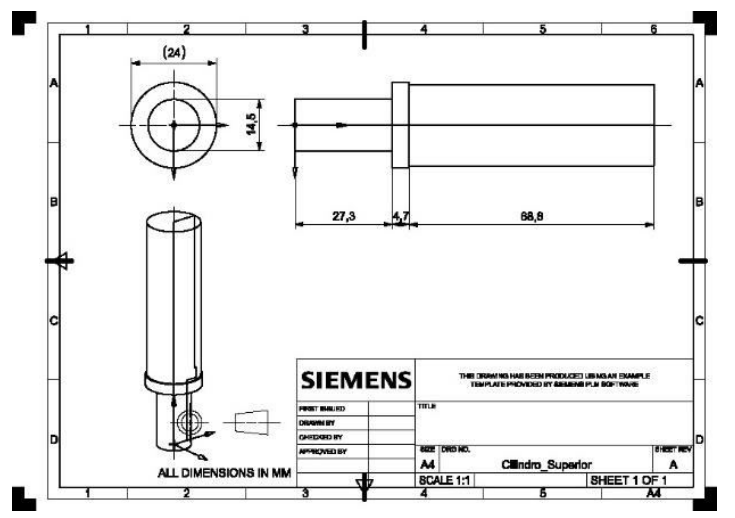

Fig. 9 Part C, the extrusion plunger (all dimensions are in $\mathrm{mm}$ )
- Material: Steel

- The volume of production: $100-1,000$ per year

- Tolerance (+-0.05)

- Surface roughness: $0.12 \mathrm{um}$

- Mass: $0.295 \mathrm{~kg}$

Table 14 Projected process using OPITZ classification

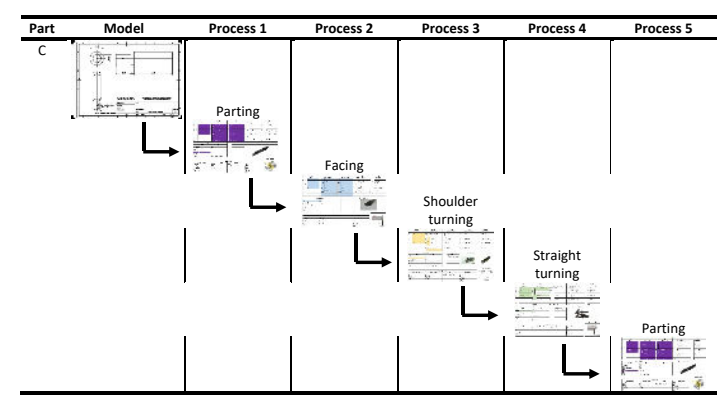

Evaluation: Select machinery or suppliers

At this stage is mandatory to use different available tools to determine a manufacturing plan. Specially designed tools can increase cost and make a bad investment if the facility means to produce all the parts. According to the synthesis phase, in Table 15 the manufacturing machine tools needed for the module are clearly stated. It also considers what parts are best suited to be acquired by outsourcing means. Complex parts need tighter tolerances and preferably must be manufacture by $\mathrm{CNC}$ although semimanual machining is also possible but time- consuming. Low volumes don't encourage the acquisition of numerical machines thus, outsourcing is preferred. Table 16 summarizes the results obtained from synthesis phase the approach for manufacturing according to complexity and cost analysis for its manufacturing.

Table 15 Machine-process relationship

\begin{tabular}{ccccc}
\hline Code & Process & Automation & Machine tool & Complex/ Non-complex parts \\
\hline LC & Linear Cutting & No & Bandsaw & $0 / 7$ \\
AC & Angular Cutting & Preferable & Lathe & $1 / 1$ \\
DR & Drilling & No & Drill press & $1 / 2$ \\
MI & Milling & Preferable & Mill & $1 / 1$ \\
TA & Tapping & No & Tap and & $0 / 2$ \\
& & & wrench & \\
CH & Chamfering & No & Mill & $0 / 1$ \\
DE & Deburring & No & Deburring tool & $0 / 7$ \\
WE & Welding & No & Welder & $0 / 7$ \\
IN & Inspecting & No & - & $0 / 9$ \\
AS & Assembling & No & - & $2 / 0$ \\
\hline
\end{tabular}


Table 16 Manufacturing approach for each part

\begin{tabular}{|c|c|c|c|c|c|}
\hline Part & Name & Processes & Complexity & In-facility & Outsorcing \\
\hline A & Motor base & $\mathrm{LC} / \mathrm{DR} / \mathrm{TA} / \mathrm{DE}$ & High & No & Yes \\
\hline B & Plunger holder & TA & High & No & Yes \\
\hline c & Plunger & $\mathrm{LC} / \mathrm{AC}$ & Medium & No & Yes \\
\hline D & Ceramic shield & - & Low & No & Yes \\
\hline E & Heating element & - & High & No & Yes \\
\hline $\mathrm{F}$ & Hopper & $\mathrm{AC} / \mathrm{DE}$ & Low & Yes & No \\
\hline G & Mould Lid & $\mathrm{LC} / \mathrm{Ml} / \mathrm{DE}$ & Medium & Yes & No \\
\hline $\mathrm{H}$ & Mould case cover & $\mathrm{LC} / \mathrm{DR} / \mathrm{DE} / \mathrm{WE}$ & Low & Yes & No \\
\hline 1 & Eject element & $\mathrm{LC} / \mathrm{CH} / \mathrm{DE}$ & Low & Yes & No \\
\hline j & Mould case & $\mathrm{LC} / \mathrm{DE} / \mathrm{WE}$ & Low & Yes & No \\
\hline $\mathrm{k}$ & Eject screw & - & Low & No & Yes \\
\hline $\mathrm{L}$ & Mould case base & $\mathrm{LC} / \mathrm{MI} / \mathrm{DR} / \mathrm{DE} / \mathrm{WE}$ & Medium & Yes & No \\
\hline
\end{tabular}

\subsubsection{Manufacturing Process Plan}

Previous phase helped to understand the processes necessary to produce each part of the module. This way, available information about machines, tools and external resources are summarized and an initial manufacturing process plan is schemed.

\section{Analysis: Identify time and costs for individual components}

On previous evaluation stage by using process selection and classification tools a wide variety of process determine an acquisition plan to produce the parts needed for the module. This will include machines, specialized cutting tools, cooling means, measurement devices, test equipment and so on (see Table 17). It also serves as a solid ground to understand requirements on the facility, e.g. electricity, emission control, waste management and workforce qualifications. This information is necessary to create cost estimations but won't be treated in this example.
Table 17 Manufacturing machines and tools to produce assembly part of the extrusion module

\begin{tabular}{|c|c|c|c|}
\hline Process & $\begin{array}{l}\text { Machine or } \\
\text { Component }\end{array}$ & Image & 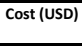 \\
\hline \multirow[t]{2}{*}{ Linear Cutting } & Bandsaw & & 400 \\
\hline & Saw & & 20 \\
\hline \multirow[t]{2}{*}{ Angular Cutting } & Lathe & & 700 \\
\hline & Inserts & & 100 \\
\hline \multirow[t]{2}{*}{ Drilling } & Drill press & & 700 \\
\hline & Drills & & 150 \\
\hline \multirow[t]{2}{*}{ Milling } & Mill & & 1000 \\
\hline & Inserts & & 150 \\
\hline Chamfering & Inserts & & 25 \\
\hline Tapping & Tapping set & & 150 \\
\hline Deburring & Deburrer & & 15 \\
\hline \multirow[t]{2}{*}{ Welding } & Welder & & 300 \\
\hline & Electrodes & & 20 \\
\hline \multirow[t]{2}{*}{ Inspecting } & Vernier & & 300 \\
\hline & Flexometer & & 5 \\
\hline \multirow[t]{2}{*}{ Assembling } & Grips & & 25 \\
\hline & Bench & & 500 \\
\hline
\end{tabular}

Synthesis: Evaluate necessities against offers in the available market

At this point it will be of extreme importance the classification of suitable parts to be produce in-facility and the ones that are better off produce by outsourcing means. Some tools are expensive and don't justify the acquisition, running and service expenses according to the production target profile. Beyond cost calculations a precedence diagram is useful to understand the flow from the raw material to the end customer (See Fig. 10). If it is noted that certain processes could lead to a further work or delay in the production due complexity, it is better to outsource to make a more agile process while reducing side-expenses and risks associated with off-expertise work.

According to the diagram is possible that two parts that were thought to be manufacturable in the facility could indeed produce higher expenses and problems than previously thought. This was visible since their manufacturing plan but with information provided at this stage a correction needs to be done to reduce risk and expenses. This way is possible to begin a sketch of activities and distribution that will lead to the production of the desired product. This will include: material sources, process timing, machining stations and complex interactions between elements. 


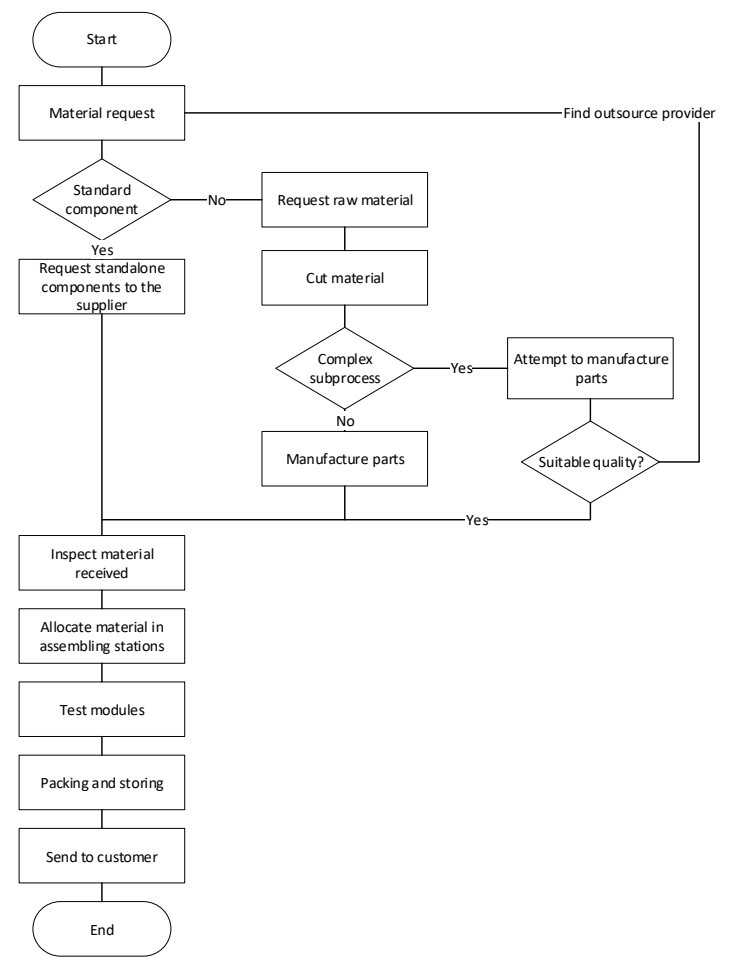

Fig. 10 Precedence diagram for the manufacturing of the extrusion module

Evaluation: Define a plan to achieve volume, quality, cost and time

With the information provided at this stage by the analysis and synthesis is possible to design a plan to produce the desired number of pieces in the projected time. At this point two branches in the production are clear, half of the parts can be manufactured in-facility while the others have to be purchased by outsourcing means. Value Stream Mapping (VSM) is a tool to consolidate and for clearly understand a plan to achieve the desired production objectives. However complex behaviours are not suitable for this tool so, plain distribution from raw material, machining processes, process stations and final customer delivery is shown in Fig. 11 and Fig. 12.

VOLUME 1,200 PER YEAR || APROX 23 DAILY PIECES

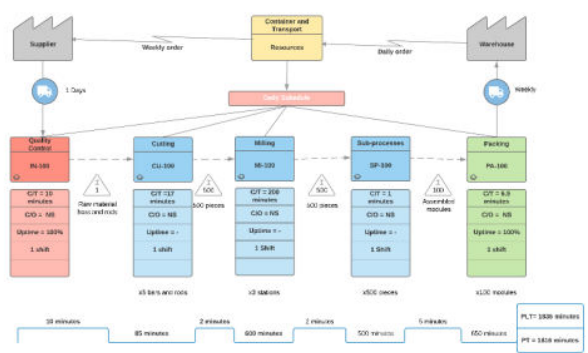

Fig. 11 VSM for in-facility machined parts

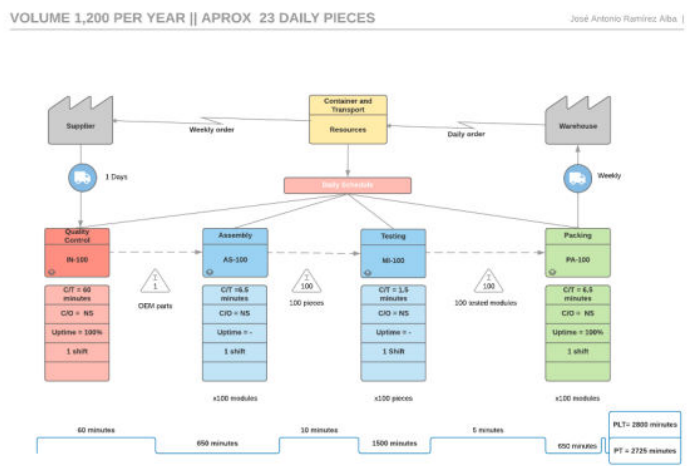

Fig. 12 VSM for outsourced parts

\subsubsection{Evaluation of Manufacturing Process Plan}

According to previous phases is possible to further develop the manufacturing plan. For this, a more complex and detailed analysis of the machinery and processing times is needed. Software solutions like Discrete Event Simulation (DES) programs can deal with the complexity to study and forecast certain scenarios. In order to design a simulation more detailed information is necessary and a process map to link all the activities inside the facility.

\section{Analysis: Determine individual activities per station}

Thanks to previous activities is possible to understand and estimate processing times on all the necessary steps to produce de module. Table 18 summarizes this data where is possible to isolate in-facility and outsource process. Manufacturing plan serves as a starting point and gives a general idea of the working facility, however, when dealing with so many events happenings at the same time, manual calculation render this work exhausting and prone to error. At this point it becomes necessary to apply all the resources so far to determine the map for the manufacturing plan. Individual activities will help to link the workflow in the next phase. 
Table 18 Individual activities chart

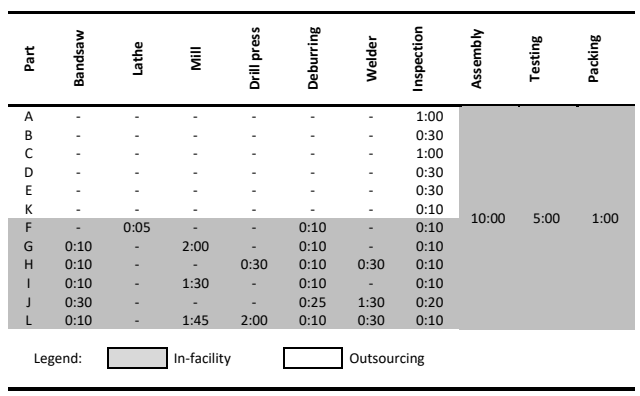

Synthesis: Simulate different scenarios

After the activities chart is made a sketch of the workflow can be made. In this case it is directly mounted on a DES software. Fig. 12. Comprises all the activities of the previous chart. On the left side sources from raw material that will be processed in-facility are declared (F, G, H, I, $J$ and L). According to the process map, each part enters a machine to be processed. For instance, piece $\mathrm{F}$ enters the lathe and then a deburring station. Each box represents a process. The logic is based on the activities chart. Side by side with some process boxes there are lists that establish the processing times for each part that enters as not everything has the same schedule. This is made for every part that is processed infacility. On the other hand, outsourced material comes from the bottom of the screen $(\mathrm{A}, \mathrm{B}, \mathrm{C}, \mathrm{D}$, $\mathrm{E}$ and $\mathrm{K}$ ). As stated in Table 19, this material is inspected and directly heads to the assembly station to join the other already processed parts. Last section corresponds to testing and packing.

The chart summarizes working (green), waiting (grey) and blocked (yellow) times, to cite a few, of the processing stations. It is clear that there are room for improvement as the bandsaw is stuck almost half of the time due bottleneck in front processes. Milling station is the only one that is working almost all the time while the other stations are waiting for material. At this point, the proposed solution is perfectly capable of producing the desired results, however, most of the machinery is wasting time due poorly optimized plan.

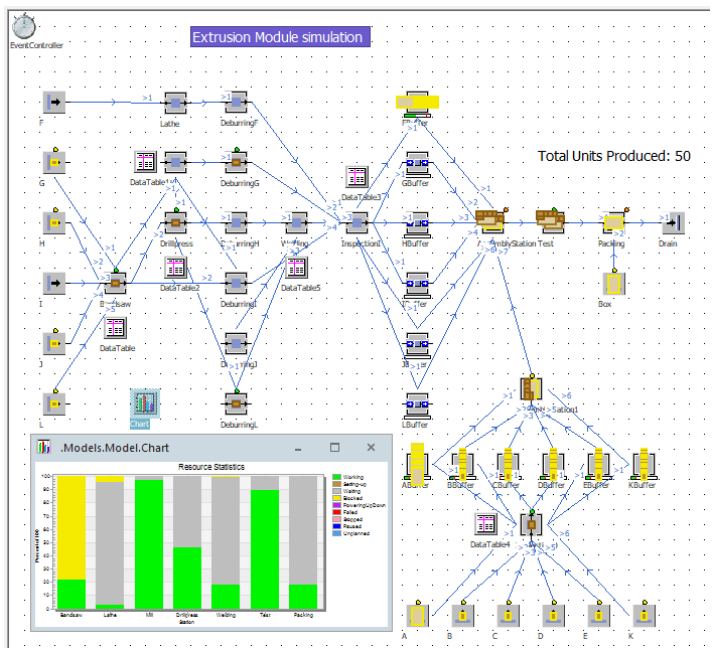

Fig. 13 Simulation of the manufacturing plant to produce Plastic Extrusion Module

\section{Evaluation: Optimise the manufacturing plan}

DES software is capable to provide solutions and analyse data to get a better solution according to the data provided. In this case, throughput chart provides a deep insight about week spots in the early designs. This can help to manually improve design or to semi automate the search for a better solution using tools like design of experiments (DoE) and genetic algorithms (GA). For the purpose of this example just manual improvement is made and different scenarios are evaluated to determine a better solution. The best one should be looked using the former optimization tools.

According to data provided by throughput chart, the bandsaw has a problem as the majority of time is stuck (See Fig. 13). This is because processing time is inferior in contrast of the subsequent stations. This render the station stuck for a great amount of time. This is solved by adding buffers between stations to store excess material. This is the way to go in a facility but was not considered in the early designs. Buffers help to equalize different processing times by storing and releasing material. Other improvements were made to the lathe adjusting the process strategy and at the end it was noticeable that a packing station had no purpose as the majority of time is waiting so, last stations merge to better use the resources. Fig 14 shows the results after making adjustments and the throughput chart clearly shows a great improvement to the early design. 


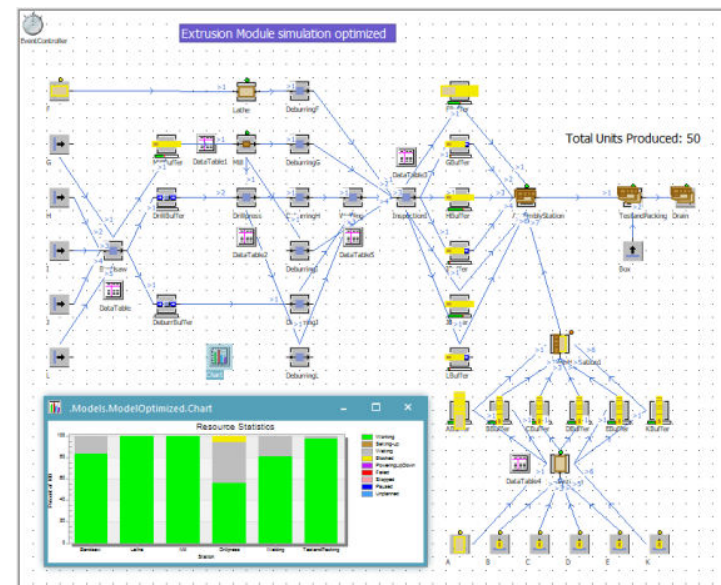

Fig. 14 Optimization of the simulation plant

The final simulation can be used as a baseline to define the final plant stations and distributions. This model aid in the search for time, process and production improvement. This way is possible to forecast scenarios and explore upgrades or pursue more ambitious production plans. This will have a significant impact on sustainability indexes.

At the end is possible to compare the activities from Table 10 to the ones developed in the extrusion module case study. It is necessary to understand that a constant assessment was conducted in parallel to determine if activities were in fact moving the process to the objective. Machinery and production strategies were considered for the production volume whereas an increment in production will necessary accommodate more sophisticated strategies. These solutions are estimated to be aligned with the objectives set at the beginning of the case and add functionalities to the Multifunctional Micromachine, providing extrusion capabilities aligned with a problematic of daily life in different recycling scenarios.

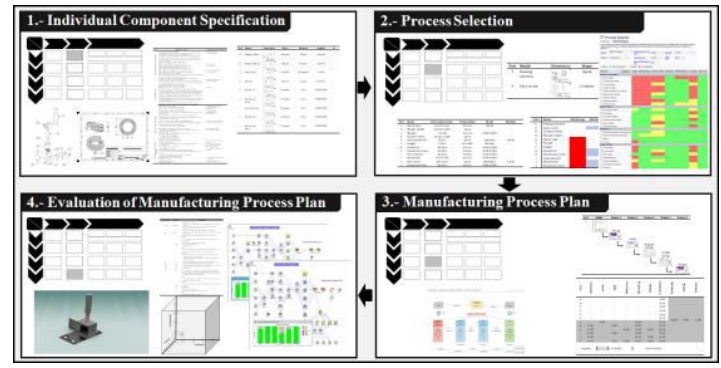

Fig. 15 Summary of the Plastic Extruder Manufacturing Process Development

In Fig. 15 there is shown a summary of the Plastic Extruder Module manufacturing process. When developing this module, the participants were observed and interviewed before and after the project was completed. The comment that was repeated the most at the end of the module was that the methodology expands the perspective of the process to be developed and allows us to follow in a structured way what we already know how to do. The manufacturing process for the Plastic Extrusion module took six weeks from its conception as part of the applications that can be performed in the MMT. The learning transmitted after using the IPPMD as a reference is that now the participants can structure an idea and break it down into achievable tasks that allows its development step by step to verify its operation.

\subsection{D Food Printer Module}

The case study presented in this article is related with food security, it targets to offer a solution around the world and cover food security. This case study concerns two nations of Latin America, Colombia and Mexico. Objectives of this research tend to contribute the state of the art in either manufacturing design and nutrition fields. The former is treated in this research, the latter would be particularised in another article. However, this project aim at providing solution to existing problems regarding nutrition. The main motivation for this project is related to the existing nutritional deficit indexes both in Colombia and in Mexico, during the realisation of this research, solutions were proposed according to resources of both nations.

There is malnutrition due to food prices and low incomes of poor and vulnerable populations. In principle, this problem is attacked from food security and formula would be described in another publication. Definition of the problem, the first approach of this research and the methodology of product design development (first entity) is exposed in (Cortés, Rodríguez, et al., 2018a). The purpose of this project is to help the causes of origin that lead to malnutrition for the most vulnerable people in both countries, children and the elderly. The implementation of the reference model has served as a guide for the development of the manufacturing process for the 3D Food Printer machine.

\subsubsection{Challenges}

The challenges addressed in this article are related to the creation of a module capable of processing edible formula into a nutritious bar for those in need. The main target of this case study was defined as the manufacturing process that involves this transformation. Decomposing the main activities needed, identify the components 
available in the market and adapt them into a manufacturing system capable of being upgraded with their sensing, smart and sustainable attributes.

During the elaboration of this project, two main approaches were treated: i) nutrition and the ii) transformation involved. Nutrition was addressed in previous work, but in this section is presented the main design of experiment to elaborate the nutritious formula. On the other hand, transformation was addressed following the methodology previously exposed (See Fig. 6) in this work. Thus, the development of the machine is related with the IPPMD reference model and particularised in the methodology proposed for the Manufacturing Process of the 3D Food Printer.

The list of challenges to overcome during the realisation of the project is presented below:

1. Nutritional characteristics. Edible formula must to be optimal for children and elderly people consumption.

2. Taste characteristic. Edible formula must be tasty for potential customers. The experiment design presented in this article resemble this characteristic among the potential customers but at the same time, mechanical attributes of the formula are tested to accomplish the declination time of the final product.

3. Mechanical characteristic. All the mechanical solutions must be standard and capable of processing the edible formula. The mechanical base is comprised of $3 \mathrm{D}$ printer components but adapted to address the viscosity needed.

4. Formula. Edible formula could be reproduced following a preparation manual that includes pre-fabrication, a series of steps and post-fabrication treatment.

5. Manufacturing system. Manufacturing process must be able to produce customizable products using the edible formula. Viscose formula is expected, mechanical components must be capable of shaping a final product.

6. Hardware specification. Every part of the manufacturing system must be specified according to standard parts.

7. Software specification. Manufacturing system should be able to process edible nutritious dough into desired forms using Computer Aided Design (CAD).

8. Modularity. The manufacturing process must be designed to be adapted into developed technology. Thus, an innocuous designed must be adapted as a whole considering the main aspects of the process.

During this case study the challenges would be treated, and the solutions found to overcome most of them when applying the methodology to create the 3D Food Printer manufacturing process. The methodology proposed was followed for the second entity of the IPPMD. Highlights of the manufacturing process development and the approach for the levels adopted are presented at the end of this section.

\subsubsection{Brief summary of the final 3D Food Printer Module}

The creation of the food extrusion module is no further explored in detail; however, a brief description of the final product is made in order to understand its process. As already explained in previous sections this module was developed using the IPPMD product engineering stages. The final result is shown on Fig. 16. The food extrusion module is an experimental design as at the moment, food printing systems are not widely used in industry nor for consumer use. Early adopters are designing machines that emulate $3 \mathrm{D}$ printing techniques to be adapted in the food industry. The purpose is to create custom-made food that can have either a particular nutritional base or simply a custom shape and flavour. The basic mechanism is similar to an extrusion system. One or several nutrition doughs are fed into a cylindric food-safety container. Then the mixture is push through a nozzle by a rotatory endless screw (A axis). Mechanical movements (X, Y and $\mathrm{Z}$ axes) allow the creation of different shapes while the material is extruded. This way, a broad spectrum of uses can be fulfilled. 


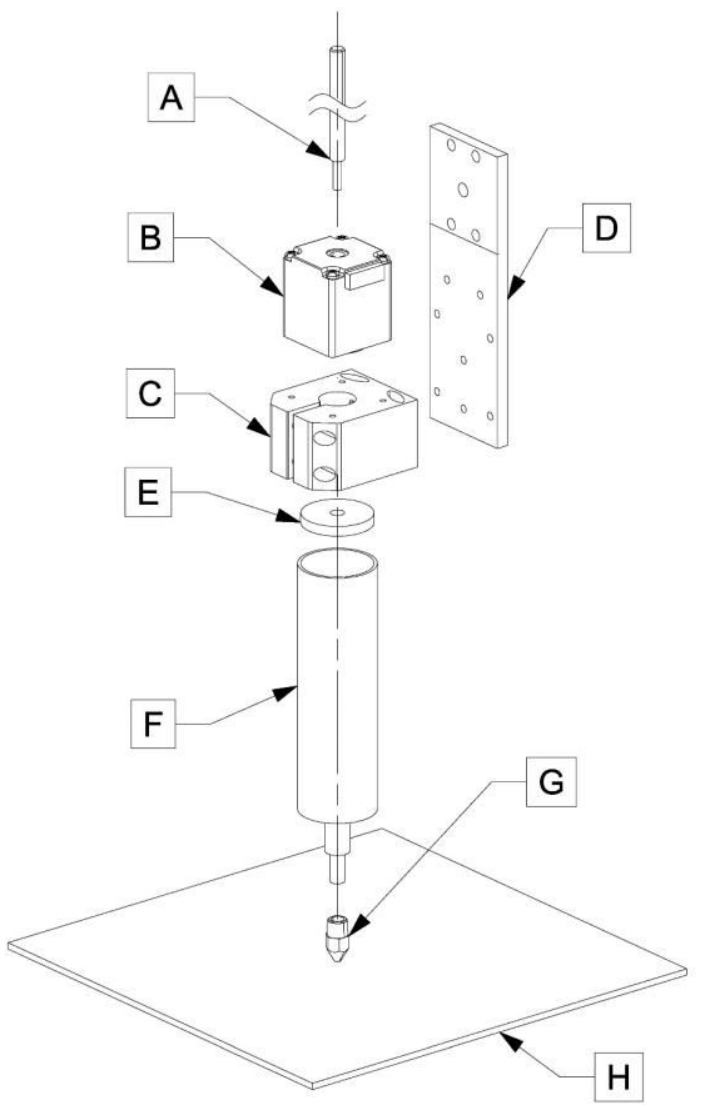

Fig. 16 Food extrusion module exploded view

Each part of the module executes a subprocess. The core of the module relies on a food safety cylinder $\mathrm{F}$ and a low friction plunger E. They act as an extrusion syringe driven by A, an endless screw. In this case, power is provided by motor B, a NEMA linear stepper. This way, force is applied only parallel to $\mathrm{Z}$ axis instead of a normal motor that creates a rotary force that would not be suitable for the syringe design. To recharge the dough inside the cylinder a specially designed holding bracket $\mathrm{C}$ provides easy mounting and dismounting operation while maintaining a robust mechanical approach to withstand pressing and releasing forces. At the end of the syringe a special designed nozzle $G$ provides shearing forces to manage nonNewtonian fluids, this allows for an easy close to linear extrusion system. Food-safety plate $\mathrm{H}$ provides a wide working space where different shapes can be formed. Fixture elements (parts C, $\mathrm{D}$ and $\mathrm{H}$ ) are attached to the base model to provide structural rigidity and mechanical power to the system. The result of the synergy between all the elements provide the functionality to perform a food extrusion process on the base model.

\subsubsection{Manufacturing Process enhancement of the 3D Food Printer System}

The first approach of the machine itself and the product development are explained in (Cortés, Rodríguez, et al., 2018b). Afterwards, the 3D Food Printer was conceived as a module of the MMT derived from the RuMT. This redefinition of the project aimed at introducing at fast paced a solution for a binational project between Mexico and Colombia. Furthermore, efforts aimed at developing a manufacturing process for the 3D Food Printer configuration. The analysis for this module will be applying the particular process manufacturing enhancement. This way the machine will benefit from the application of the methodology.

A few considerations are taken into account. "beginning of the work in process" Extrusion system is part of a system that manufactures nutrimental products. The amount of edible formula that is going to be processed daily is near $10 \mathrm{Kg}$ per day, thus 50 bars of $200 \mathrm{~g}$ are expected in one labour day, reaching up to 1000 per month. In the production line the manufacturing process contemplates the premixed formula but is to be prepared daily, a forming process is expected to shape the bars and the last process in the line aims for packing and transported if necessary. To develop the Manufacturing Process, the challenges were discussed among the research team to introduce the functionalities needed.

The manufacturing process integrated multidisciplinary work and skills to come with an optimal process with available resources in the market. Thus, the methodology was selected to guide the realisation of stages in the designing process. Following the methodology exposed in Fig. 4 aided by the toolbox presented in Table 1, there has been developed the Manufacturing Process of the 3D Food Printer. The procedure is the one which is stated at the end of section 2 . Definition of entity, instantiation and deployment.

\section{i) Definition of Manufacturing Process}

Analysing the product specification sheet and the edible formula, it was defined that the manufacturing process could be decomposed as shown in Fig. 17. The sequence of steps makes possible to measure process, service and productivity variables. 


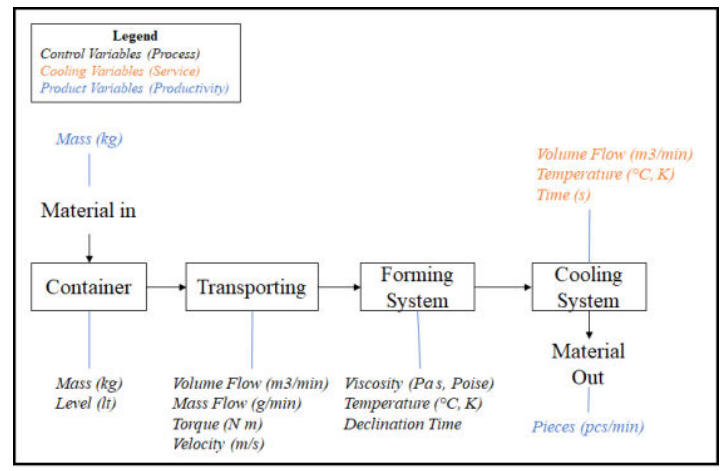

Fig. 17 Decomposition of the 3D Food Printer Manufacturing Process

Besides, the edible formula described in previous work was redesigned using the following Design of Experiments Standard Table 19.

Table 19 Design of Experiments for defining the critical components of the Edible Formula

\begin{tabular}{|c|c|c|c|c|c|c|c|c|}
\hline Run & Actual Run & A & B & C & D & $E$ (Fixed) & $\mathrm{F}$ (Covariate) & 9 (Disturbance) \\
\hline 1 & 9 & - & - & - & - & 25 & Yes & 1.4537 \\
\hline 2 & 14 & + & - & - & - & 25 & Yes & 1.6724 \\
\hline 3 & 2 & - & + & - & - & 25 & Yes & 1.6608 \\
\hline 4 & 15 & + & + & - & - & 25 & No & 1.1024 \\
\hline 5 & 6 & - & - & + & - & 25 & Yes & 1.7158 \\
\hline 6 & 5 & + & - & + & - & 25 & No & 0.9632 \\
\hline 7 & 11 & - & + & + & - & 25 & Yes & 1.5747 \\
\hline 8 & 16 & + & + & + & - & 25 & Yes & 1.0034 \\
\hline 9 & 3 & - & - & - & + & 25 & Yes & 1.1866 \\
\hline 10 & 13 & + & - & - & + & 25 & Yes & 0.9043 \\
\hline 11 & 8 & & + & - & + & 25 & No & 1.4089 \\
\hline 12 & 10 & + & + & - & + & 25 & Yes & 1.1245 \\
\hline 13 & 1 & - & - & + & + & 25 & No & 1.2671 \\
\hline 14 & 7 & + & - & + & + & 25 & Yes & 0.9959 \\
\hline 15 & 12 & . & + & + & + & 25 & Yes & 0.9854 \\
\hline 16 & 4 & + & + & + & + & 25 & Yes & 1.6063 \\
\hline & \multicolumn{2}{|c|}{ B \& C Combinations } & $B$ & c & & & & \\
\hline & \multirow{2}{*}{\multicolumn{2}{|c|}{$\begin{array}{l}\text { Fruit } 1 \\
\text { Frutit }\end{array}$}} & - & 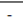 & & & & \\
\hline & & & $-1+$ & $+1-$ & & & & \\
\hline & & + & + & & & & \\
\hline
\end{tabular}

During the design of experiments, multiple components were analysed, some were fixed and measured to define the final formula to be printed by the system. The combination of fruits was selected according to available resources in both countries. The formula is viscous and for the forming system of the manufacturing process, it was needed to study the mechanical behaviour to select optimal components for the module. Final decision of the formula contemplated a tasty formula ranked from 0-10 among 100 participants, maximizing the flavour with the mixture of components and, maximizing declination time from a thin wall of $4 \mathrm{~mm}$ width (standard 3D printer nozzle), $5 \mathrm{~cm}$ length and $3 \mathrm{~cm}$ height.

\section{ii) Instantiation}

The sequence of activities is defined in Fig. 4 , where engineering activities (analysis, synthesis and evaluation) coupled with tollgates are used to guide designers into the definition of the Manufacturing Process.

Every activity is oriented to assure there is enough proof that the manufacturing process developed is effective and functional. During the 3D Food Printer Module development, there were realised all activities proposed. Activities make use of the tools presented in Table 1, but there is no restriction of including those techniques that complement the area in which the manufacturing process is developed.

\section{iii) Deployment}

The third activity is oriented to characterise the manufacturing process which is being designed or upgraded. Here are selected the tools and techniques which are going to be carried out. For the 3D Food Printer Module, the particular model for the process development is shown in Table 20. Which presents the stage that was developed, the activities carried out and the tool which documented the activities proposed.

Table 20 Manufacturing Process Development. 3D Food Printer Module

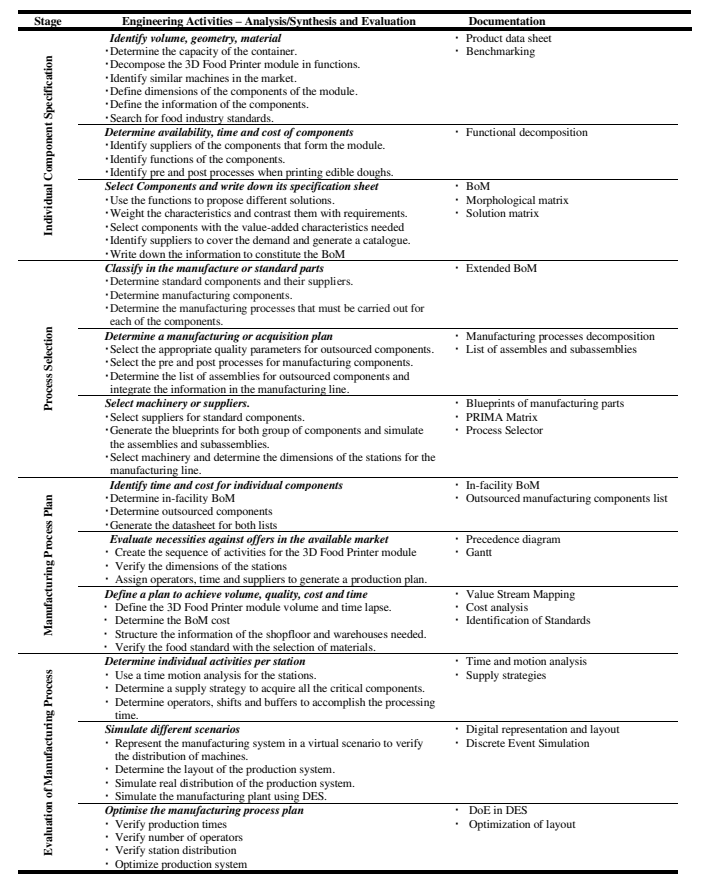

Application of the instantiation stages and highlights when developing the manufacturing process are delved in the following subsections. 


\subsubsection{Individual Component Specification}

After the particular model of the 3D Food Printer Module was defined, the sequence of activities has been carried out. To define the analysis activity of individual component specifications, the tool selected was benchmarking to understand how the manufacturing process for food was carried out at low scale. The components that the project demanded aimed for modularity, reconfigurability and due to the viscosity of the edible formula, there were identified that the main restrictions were the nozzle and plunger system. Thus, an extruder comparison was made to identify the standard components for food extrusion to incorporate in the 3D Food Printer module (See Table 21).

Table 21 Extruder comparison of standard components for food extrusion

\begin{tabular}{|c|c|c|c|}
\hline Brand & Type & Cost (USD) & Usage \\
\hline Velleman & $\begin{array}{c}\text { Semi- automatic } \\
\text { Syringe }\end{array}$ & $\$ 100.00$ & Thick Paste \\
\hline Bocusini & $\begin{array}{l}\text { Semi- automatic } \\
\text { Syringe }\end{array}$ & $\$ 250.00$ & Thick Paste \\
\hline Zmorph & $\begin{array}{c}\text { Semi- automatic } \\
\text { Syringe }\end{array}$ & $\$ 300.00$ & Thick Paste \\
\hline byFlow Focus & Syringe & $\$ 330.00$ & Thick Paste \\
\hline Foodini & $\begin{array}{c}\text { Semi- automatic } \\
\text { Syringe }\end{array}$ & $\$ 800.00$ & Thick Paste \\
\hline Discov3ry & $\begin{array}{c}\text { Semi-automatic } \\
\text { Syringe }\end{array}$ & $\$ 1,300.00$ & $\begin{array}{c}\text { Sillicone } \\
\text { Nutella } \\
\text { Wood filler }\end{array}$ \\
\hline ViscoTec & $\begin{array}{c}\text { Syringe - } \\
\text { Endless screw }\end{array}$ & $\$ 1,500.00$ & $\begin{array}{c}\text { Continuous flow } \\
\text { of viscous } \\
\text { material }\end{array}$ \\
\hline CreateBot & $\begin{array}{l}\text { Semi- automatic } \\
\text { Syringe }\end{array}$ & $\$ 2,115.00$ & $\begin{array}{c}\text { Thick Paste, } \\
\text { Embedded }\end{array}$ \\
\hline ChocEdge & Syringe & $\$ 2,999.00$ & $\begin{array}{c}\text { Chocolate, } \\
\text { Unavailable } \\
\text { printhead }\end{array}$ \\
\hline Mmuse Touchscreen & $\begin{array}{c}\text { Semi- automatic } \\
\text { Syringe }\end{array}$ & $\$ 5,499.00$ & $\begin{array}{l}\text { Chocolate, } \\
\text { Embedded }\end{array}$ \\
\hline Own & $\begin{array}{l}\text { Semi- automatic } \\
\text { Syringe }\end{array}$ & 65.00 & Thick Paste \\
\hline
\end{tabular}

Synthesis activity was determined by the availability and presence in the market. If the component could be acquired without the whole system, then modularity is viable to include in the machine developed internally. On the other hand, evaluation required a functional decomposition and comparison among multiple components that were tested (See Table 22).

There was a comparison between different alternatives available in the market. Suppliers were identified with their respective cost and demand expected for the products. The functional decomposition accomplished the motives of the designers and provided a base for the composition of the manufacturing system.
Table 22 Functional decomposition of the 3D Food Printer manufacturing process

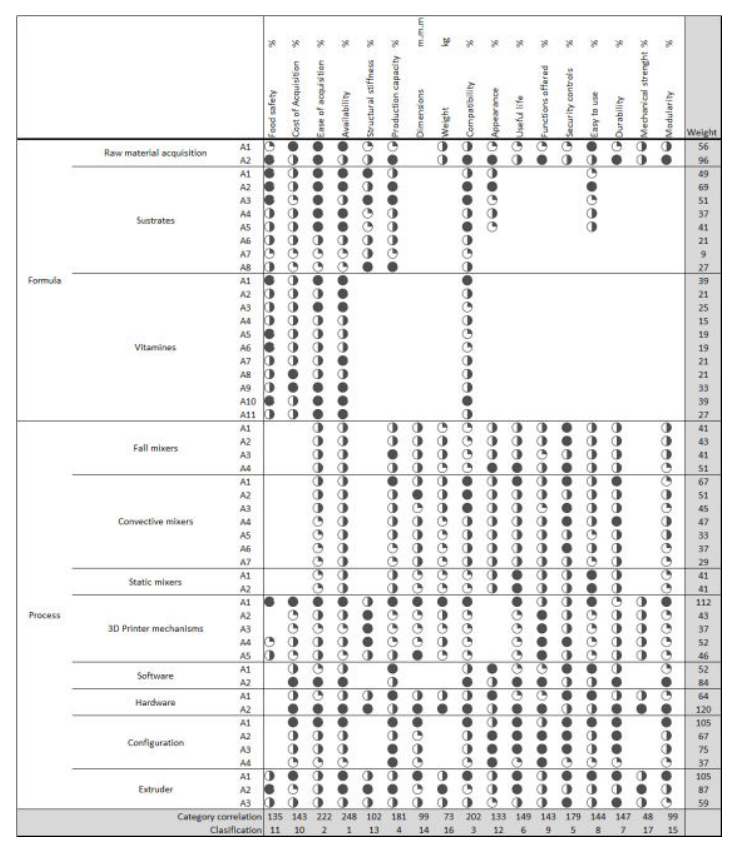

\subsubsection{Process Selection}

Most of the components were based on three materials. Stainless steel for those that were in contact with the food (container, nozzle), aluminium for the structural machine and innocuous plastic for the plunger system. This was the initial classification to proceed with standard or manufacture components.

Standard components required an acquisition plan relied on the availability, quantity, cost and quality of the pieces from the suppliers. An extract of the Bill of Materials of the machine is presented in Table 23.

Table 23 Extract of Bill of Materials.

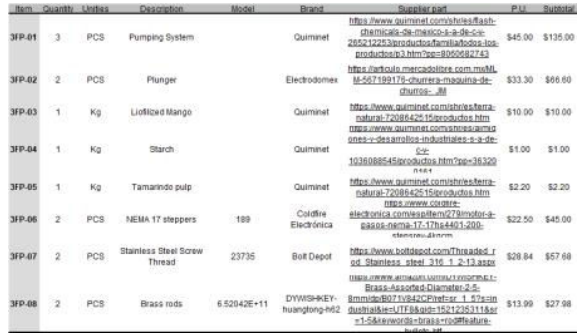

Manufacture components were produced as part of the manufacturing process for the 3D Food Printer Module. Most of these manufacturing components correspond to structural base of the machine that incorporates the module. For the analysis of these components, the technique applied is the use of PRIMA Matrix as well as 
Process Selector. It is included as an example, the support of the extruder mounted in $\mathrm{Z}$ axis (See Fig.18).
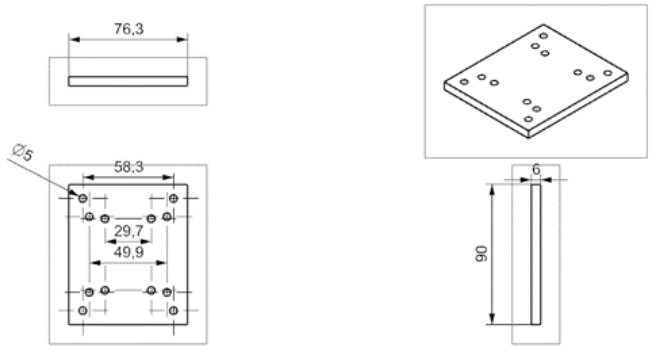

Fig. 18 Support of the extruder design (all dimensions are in $\mathrm{mm}$ )

The material selected was aluminium, there was an estimation of 100-1000 pieces per year, tolerance is +-0.2 in the respected unit, surface roughness of the material was 0.12 Micro-m and the mass of the components rounds $0.12 \mathrm{~kg}$. With this information of the components, an analysis was done using PRIMA matrices leading to Table 24.

Table 24 Identification of manufacturing processes to produce the support of the extruder

\begin{tabular}{|c|c|c|c|c|c|c|c|c|}
\hline $\begin{array}{l}\text { Shaping } \\
\text { process } \\
\end{array}$ & $\begin{array}{l}\text { Material } \\
\end{array}$ & $\begin{array}{l}\begin{array}{l}\text { Batch } \\
\text { Size }\end{array} \\
\end{array}$ & Shape & Mass & $\begin{array}{l}\text { Thickness } \\
\text { nat }\end{array}$ & Tolerance & $\begin{array}{l}\begin{array}{l}\text { Surface } \\
\text { roughness }\end{array} \\
\end{array}$ & Total \\
\hline Sand casting & 1 & 1 & & & & & & \\
\hline Die casting & 1 & & & 1 & 1 & & & $\begin{array}{l}3 \\
5\end{array}$ \\
\hline $\begin{array}{l}\text { Investment } \\
\text { casting }\end{array}$ & 1 & 1 & & & & 1 & & \\
\hline $\begin{array}{l}\text { Low- } \\
\text { pressure } \\
\text { casting }\end{array}$ & 1 & & & & & & & \\
\hline Forging & 1 & 1 & & 1 & 1 & & & 4 \\
\hline $\begin{array}{l}\text { Extrusion } \\
\text { Sheet }\end{array}$ & $\begin{array}{l}1 \\
1\end{array}$ & & & 1 & $\begin{array}{l}1 \\
1\end{array}$ & 1 & & $\begin{array}{l}2 \\
4\end{array}$ \\
\hline $\begin{array}{l}\text { forming } \\
\text { Powder }\end{array}$ & 1 & & & 1 & 1 & & & 3 \\
\hline $\begin{array}{l}\text { methods } \\
\text { Electro- }\end{array}$ & 1 & 1 & 1 & 1 & 1 & & & 5 \\
\hline $\begin{array}{l}\text { machining } \\
\text { Conventional }\end{array}$ & 1 & 1 & 1 & 1 & 1 & 1 & & 6 \\
\hline
\end{tabular}

Alternatively Process Selector is a viable alternative online (https://www.custompartnet.com/ process-selector) that aided designers to select in a more effective manner the processes with the components identified. For the support of the extruder, a conventional machining was the manufacturing process to produce the volume required per year.

This analysis was carried out to determine the type of process that should be included as part of the manufacturing process plan.

\subsubsection{Manufacturing Process Plan}

Standard components required the acquisition plan and delivery directly to the manufacturing lines. Nonetheless, manufacturing components have been identified with their respective manufacturing processes and characteristics, machinery was selected for accomplishing the shaping or finishing of the components.

An extract from the selection of machinery, tooling and spare components is shown in Table 25. Machinery was used to add value, providing certain quality and finishing to the components.

Table 25 Needed material to produce manufacturing process of the 3D Food Printer Module

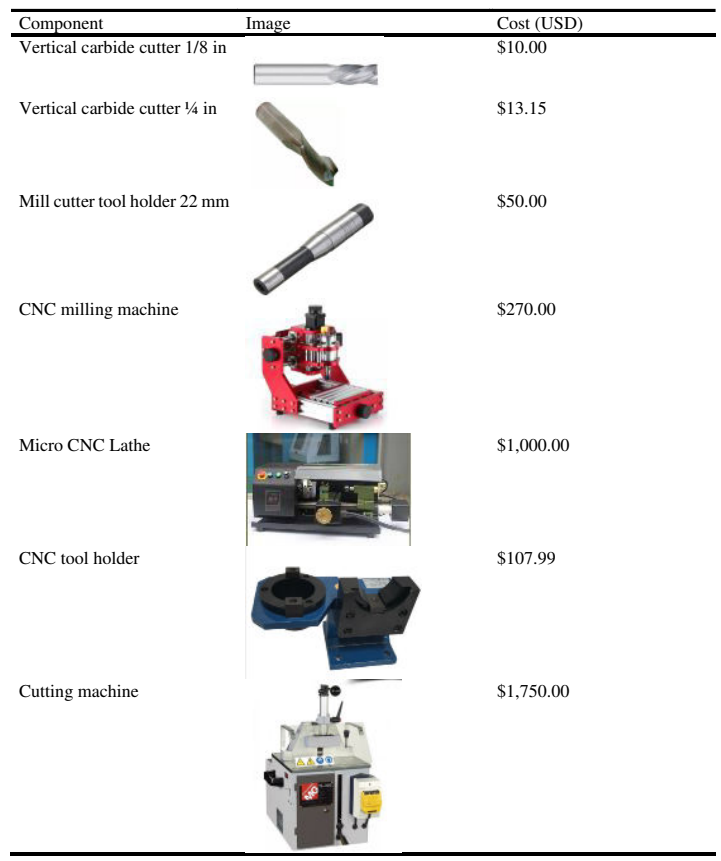

Then, a precedence diagram was designed to follow during the creation of the manufacturing process of the 3D Food Printer Module. For the support of the extruder, the activities that must be followed are (See Fig. 19):

1. Standard components are requested weekly (extruder and plunger system)

a. There is an inspection of standard components

b. There are allocated in the assembly stations

2. There is a request for raw material of manufacture components that are delivered ever three days

3. The raw material is cut in small plates to be manufactured

4. Small plates are shaped to the geometry needed

5. Small manufactured pieces are transported to a milling machine

6. Pieces are transported to finishing treatments for smoothing the surface

7. Finished components are allocated in assembly stations 
8. Assembled components are packed

9. Packages are sent to customers

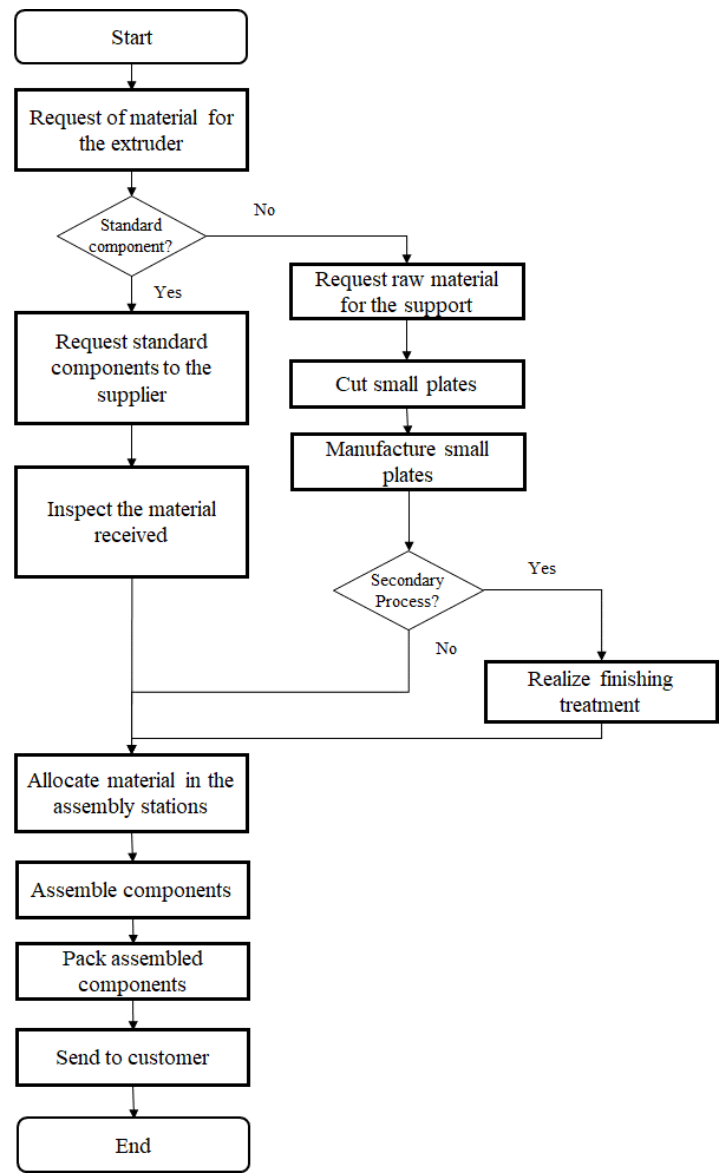

Fig. 19 Precedence diagram of the extruder's support manufacturing process

Sequence of activities have been designed for each subsystem of the manufacturing process. Thus, components that correspond to the container are grouped to proceed with the productivity plan. The Value Stream Mapping (VSM) technique was defined to allocate the processes in the manufacturing plant. Below is presented the VSM for the container and transporting subprocesses of the 3D Food printer module manufacturing process (See Fig. 20).

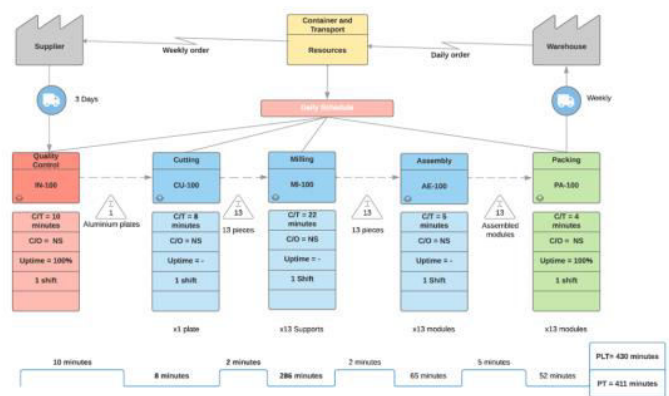

Fig. 20 Value Stream Mapping for the Container and Transport Subprocesses

Then, continuing the definition of the manufacturing plan, it was required a cost analysis of the complete module. In Fig. 21 there is observed a common representation of the cost associated to manufacturing plants. The percentages presented are associated with the name described. Thus, Direct material cost usually rounds 42.2 percent of the total cost of generating a product, direct labour cost rounds 13 percent and general administrative 12 percent respectively.

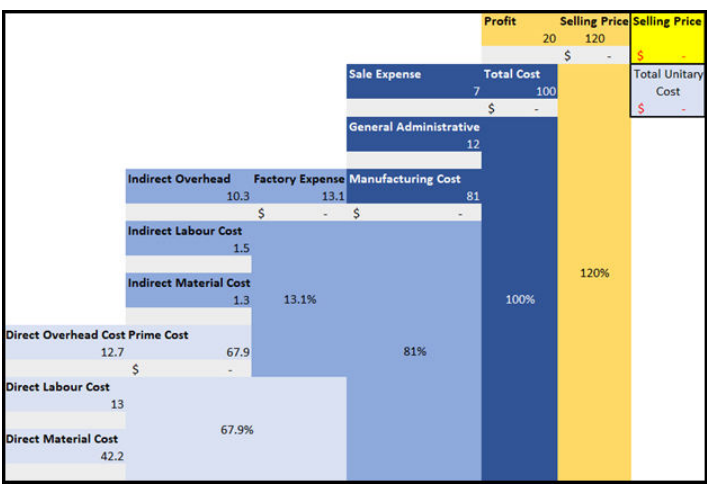

Fig. 21 Costs associated to manufacturing expenses

Besides, in Table 26 a cost analysis extract of the manufacturing process of the 3D Food Printer module is presented.

Table 26 Cost analysis extract

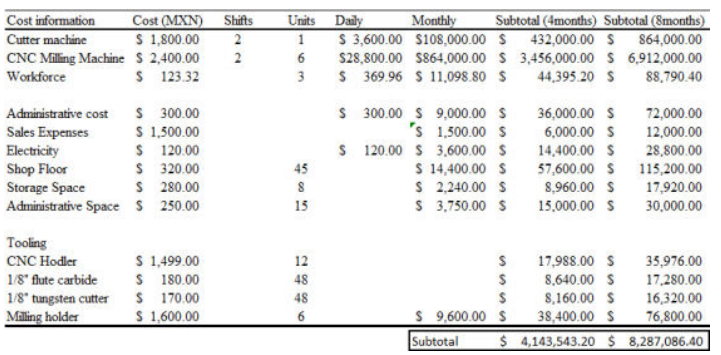

The VSM and cost analysis were used to define the manufacturing process plan of the 
module. Nonetheless, evaluation was required before continuing to production.

\subsubsection{Evaluation of Manufacturing Process Plan}

An evaluation of the manufacturing process plan was carried out starting from quality, times and movements. Quality was compared with the machinery selected to address the finishing surface of the subsystems and the suppliers selected to achieve certain quality before assemblies. On the other hand, there was run a time and motion study in the assembly station with one batch of components. In Table 27 is presented the study ran for the container and transport subprocesses of the module.

Table 27 Time and Motion study in the assembly station

\begin{tabular}{cccccc}
\hline Dactivity & Time in & Time out & Total time (minutes) & Average Time (minutes) & Total time/Av time \\
\hline 1 & $15: 16$ & $15: 20$ & 4 & 2 & 2.00 \\
2 & $15: 20$ & $15: 25$ & 5 & 4 & 1.25 \\
3 & $15: 25$ & $15: 29$ & 4 & 2 & 2.00 \\
4 & $15: 29$ & $15: 36$ & 7 & 5 & 1.40 \\
5 & $15: 36$ & $15: 41$ & 5 & 3 & 1.67 \\
6 & $15: 41$ & $15: 48$ & 7 & 5 & 1.40 \\
7 & $15: 48$ & $15: 50$ & 2 & 1 & 2.00 \\
8 & $15: 50$ & $15: 54$ & 4 & 3 & 1.33 \\
\hline
\end{tabular}

After the initial study, there were some changes to adjust a better distribution of the operators and operations that must be done due to complexity of shapes. These changes have reduced the time of assembly operations in the first steps around 25 percent of the time needed (See Table 28).

Table 28 Time and Motion results in the assembly station

\begin{tabular}{cccccc}
\hline D activity & Time in & Time out & Total time (minutes) & Average Time (minutes) & Total time/Av time \\
\hline 1 & $15: 16$ & $15: 20$ & 4 & 2 & 2.00 \\
$2 \& 5$ & $15: 20$ & $15: 27$ & 7 & 5 & 1.40 \\
3 & $15: 27$ & $15: 31$ & 4 & 2 & 2.00 \\
4 & $15: 31$ & $15: 38$ & 7 & 3 & 2.33 \\
$6 \& 7$ & $15: 38$ & $15: 44$ & 6 & 4 & 1.50 \\
8 & $15: 44$ & $15: 48$ & 4 & 3 & 1.33 \\
\hline
\end{tabular}

Time presented in this study was introduced in Tecnomatix Plant Simulation software by Siemens, to generate discrete evet simulation scenarios. The manufacturing process was evaluated and optimised with the simulation tool (See Fig. 22).

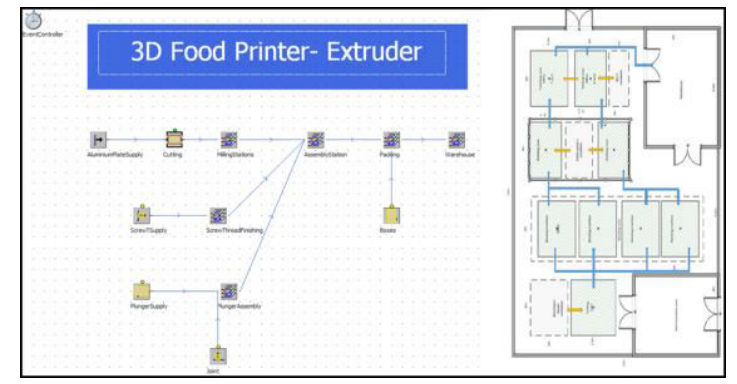

Fig. 22 3D Food Printer Module - Extruder Simulation and Layout

All in all, the 3D Food Printer Module was first designed using $\mathrm{NX}$ for $\mathrm{CAD}$, then, some components were acquired to test the edible formula under different parameters mounted in the system and currently, some adaptions are done to adapt the final components of the machine (See Fig. 23).

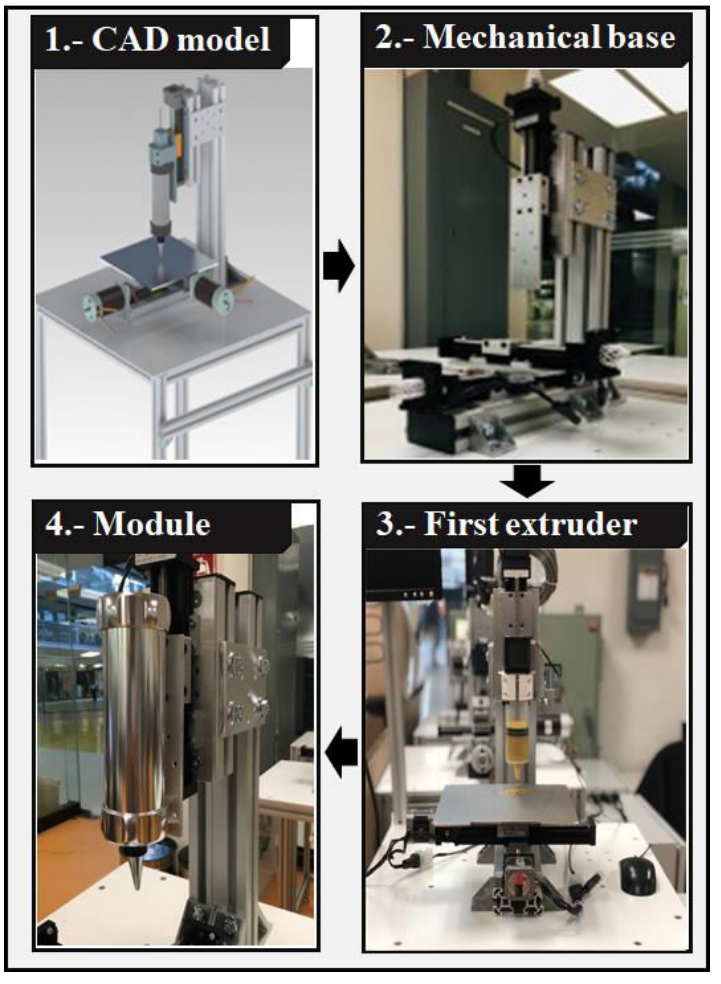

Fig. 23 Evolution of the 3D Food Printer Module

A summary is presented in Fig. 25 about the steps involved to develop the 3D Food Printer Module following the Manufacturing Process methodology.

The module complements the development of the MMT. It was developed to achieve a feasible solution for a binational project. 


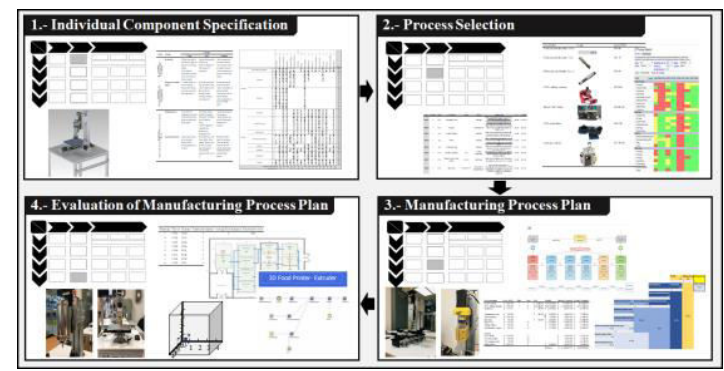

Fig. 24 Summary of the 3D Food Printer Module Manufacturing Process Development

In Fig. 24 there is shown a summary of the 3D Food Printer Module manufacturing process. The participants' learning focuses on understanding the manufacturing process that they want to develop, analysing the final product of that manufacturing process to make decisions about the components to be produced and acquired, and understanding that the module is part of a manufacturing system for the MMT. The participants were observed before and after the project was completed. They had previous knowledge in diverse areas, however, the key moment that allowed the development of the module in seven weeks, occurred when decomposing the manufacturing process and observing it as tasks, following the IPPMD scheme for a particular case in the development of the 3D Food Printer.

\section{Conclusions}

The IPPMD aims at being a general procedure that could be adapted not only to any type of manufacturing system, but also to provide an integral perception to stakeholders to enhance the current state of the manufacturing system. During the case studies presented in the article, designers have been generating documentation which complements the product development entity to produce a robust manufacturing system. This information is useful when pursuing growth in the manufacturing firm. But at the same time the reference framework is enriched with the comprehension of the system to allocate the current state to be upgraded, if needed, with the adoption of technology or innovative techniques. The versatility of the methodology is where the contribution points out, as it offers guidelines for novel designers but contemplates a systematic revision for the experts.

The engineering activities and toolbox provided must be then, used to establish the path to follow along the instantiation of the methodology. This structure is sturdy to detect failures at tollgates, providing feedback before continuing with the development, thus, an optimised manufacturing process is expected at the end of the four design stages.

For the case studies, there was an analysis of one hundred and fifty participants that learned the IPPMD reference framework and applied it to different cases. Thus, during the implementation of the case studies:

i) For the Multifunctional Micromachine, designers determined that the goal of this technology is to aid in a variety of tasks. It could be used to teach, put in practice principles and create manufacturing products for MSMEs and entrepreneurs. Furthermore, the process was structured with engineering activities and tools or technique recommended, following the methodology with the four design stages of the product, manufacturing process and manufacturing system entities to upgrade existing technology and lead into modularity and flexibility offered by the Multifunctional Micromachine.

ii) For the Plastic Extruder Module development, it adds functionalities to the machine regarding plastic waste. The participants were aware of the MMT, they analysed megatrends, the numbers of plastic that is not recyclable and came up with the idea of a Module that could attack that existing problem. The idea was accepted and used as a multidisciplinary project for industrial and mechatronics engineering undergraduates. The future of this project is to incorporate it as a module of the Micromachine Tool and recycle plastic or adapt moulds for rapid prototyping.

iii) For the 3D Food Printer Module development, as part of a binational project, the main goal of this module is to offer to the most in need, a viable alternative to produce nutritious ailments that could be prepared in situ or transported to rural communities, the objective of this module is to pack the machine and produce nutritious enriched bars that contain the vitamins needed. The case study is presented and emphasises the manufacturing process development, as it would produce the edible bars. It is a module that could be easily adaptable to the Multifunctional Micromachine, and the future goal of this technology is to connect nutritionists with patients to produce their own customizable food for individual requirements.

The MMT is a technology developed at Tecnologico de Monterrey, under the patent Reconfigurable Micromachine Tool. The two modules exposed during this work complemented 
the CNC functionalities offered in the machine thus, enriching its capacity to be used for academic, rapid prototyping or industrial (lowscale) purposes. The Plastic Extruder Module arose as a feasible solution to process collected PET at the institution, whilst the 3D Food Printer Module seeks to offer a viable alternative to process a mixture of vitamins at rural places. Besides, as the technology is affordable, there is an opportunity area to offer customised solutions at home.

There are ongoing projects to test this methodology at i) industrial engineering courses, ii) research stays to learn rapid product development with their respective manufacturing process and iii) bootcamps to teach entrepreneurs the model to provide them with tools to create their own businesses. Short-termed future work would be centred in adding modules to the MMT to teach an integral methodology which incorporates the vision of a complete manufacturing system and enterprise. Further development is expected in the manufacturing system entity as its complexity poses a challenge for documenting and structuring into the IPPMD. Furthermore the proposed methodology will aim at include sensing, smartness and sustainable characteristics that aid in the development process.

\section{Acknowledgements}

The research presented in this publication corresponds to the binational project MexicoColombia with the collaboration of the universities, Tecnologico de Monterrey (ITESM) and Universidad de Los Andes (UniAndes). With GRANT P16.700099.001/02-04

The authors thank both Tecnologico de Monterrey and CONACyT for their participation in the development of this research and scholarships.

\section{References}

Bainbridge, W. S., \& Roco, M. C. (2006). Managing nano-bio-info-cogno innovations. Springer.

Chavarría-Barrientos, D., Camarinha-Matos, L. M., \& Molina, A. (2017). Achieving the sensing, smart and sustainable "everything." Working Conference on Virtual Enterprises, 575-588. Springer.

Chavarría-Barrientos, D., Miranda, J., Cortés, D., \& Molina, A. (2018). Experiences in Product, Process and Manufacturing Systems
Development in Industrial Engineering Courses: The Integrated Manufacturing System Course as Case Study. In Proceedings of the 12th International Multi-Conference on Society, Cybernetics and Informatics: IMSCI 2018 (pp. 7-13).

Chung, C. C.-W., Choi, J.-K., Ramani, K., \& Patwardhan, H. (2005). Product Node Architecture: A Systematic Approach to Provide Structured Flexibility in Distributed Product Development. Concurrent Engineering, 13(3), 219-232. https://doi.org/10.1177/1063293X05056472

Cortés, D., Chavarría-Barrientos, D., Ortega, A., Falcón, B., Mitre, L., Correa, R., ... Molina Gutiérrez, A. (2018). A Framework to Support Industry 4.0: Chemical Company Case Study. In L. M. Camarinha-Matos, H. Afsarmanesh, \& Y. Rezgui (Eds.), IFIP Advances in Information and Communication Technology (Vol. 534, pp. 387395). https://doi.org/10.1007/978-3-319-991276_33

Cortés, D., Ramírez, J., \& Molina, A. (2018). Integrated Product, Process and Manufacturing System Development Reference Model: Research Summer as case study. https://doi.org/10.18687/LACCEI2018.1.1.278

Cortés, D., Rodríguez, B. E., Gutiérrez, J. A., Welti, J., Serna, S., Molina, A., ... Medina, J. (2018a). Integrated Product, Process and Manufacturing System Development. 2018 IEEE International Conference on Engineering, Technology and Innovation (ICE/ITMC), 1-9. https://doi.org/10.1109/ICE.2018.8436275

Cortés, D., Rodríguez, B. E., Gutiérrez, J. A., Welti, J., Serna, S., Molina, A., ... Medina, J. (2018b). Integrated Product, Process and Manufacturing System Development. 2018 IEEE International Conference on Engineering, Technology and Innovation (ICE/ITMC), $1-9$. https://doi.org/10.1109/ICE.2018.8436275

Cronin, C., Conway, A., \& Walsh, J. (2019). Flexible manufacturing systems using IIoT in the automotive sector. Procedia Manufacturing, 38, 1652-1659.

https://doi.org/https://doi.org/10.1016/j.promfg.2 020.01 .119

Hehenberger, P. (2009). Application of Mechatronical $\mathrm{CAD}$ in the Product Development Process. Computer-Aided Design and Applications, 6(2), 269-279.

https://doi.org/10.3722/cadaps.2009.269-279

INEGI. (2018). Encuesta Nacional sobre Productividad y Competitividad de las Micro, Pequeñas y Medianas Empresas (ENAPROCE 2018). Retrieved from 
https://www.inegi.org.mx/programas/enaproce/2 018/

Kashyap, R. (2019). Chapter 10 - Miracle of Deep Learning Using IoT (A. K. B. T.-D. L. and P. C. E. for B. S. Sangaiah, Ed.) https://doi.org/https://doi.org/10.1016/B978-012-816718-2.00017-8

Koren, Y., Heisel, U., Jovane, F., Moriwaki, T., Pritschow, G., Ulsoy, G., \& Van Brussel, H. (1999). Reconfigurable Manufacturing Systems. CIRP Annals, 48(2), 527-540. https://doi.org/https://doi.org/10.1016/S00078506(07)63232-6

Lowe, E. (2005). CHAPTER 4 - Economic Solutions (F. J. Agardy \& N. L. B. T.-E. S. Nemerow, Eds.). https://doi.org/https://doi.org/10.1016/B978012088441-4/50005-8

Molina, A., Ponce, P., Miranda, J., \& Cortés, D. (2020). Sensing, Smart and Sustainable Technologies for enabling Intelligent Manufacturing Systems in Industry 4.0 (First). Springer.

Molina, A., Romero, D., \& Ponce, P. (2016). Desarrollo rápido de productos innovadores para mercados emergentes. Retrieved from https://www.coursera.org/learn/innovacion?

Müller, J. M., \& Voigt, K.-I. (2018). The Impact of Industry 4.0 on Supply Chains in Engineer-toOrder Industries - An Exploratory Case Study. IFAC-PapersOnLine, 51(11), 122-127. https://doi.org/https://doi.org/10.1016/j.ifacol.201 8.08.245

Porter, M. E., \& Heppelmann, J. E. (2014). How smart, connected products are transforming competition. Harvard Business Review, 92(11), 64-88.

Price Waterhouse Coopers. (2015). The World in 2050 Will the shift in global economic power continue? Retrieved from https://www.pwc.com/gx/en/issues/theeconomy/assets/world-in-2050-february2015.pdf

Ragatz, G. L., Handfield, R. B., \& Petersen, K. J. (2002). Benefits associated with supplier integration into new product development under conditions of technology uncertainty. Journal of Business Research, 55(5), 389-400.

Ramírez-Cadena, M., Miranda, J., Tello-Albarrán, G., Dávila-Ramírez, O., \& Molina, A. (2012). Reconfigurable didactic microfactory with universal numerical control. IFAC Proceedings Volumes, 45(6), 463-468.

Ratchev, S. M., \& Hirani, H. (2001). Concurrent requirement specification for conceptual design of modular assembly cells. Proceedings of the 2001 IEEE International Symposium on
Assembly and Task Planning (ISATP2001). Assembly and Disassembly in the Twenty-First Century. (Cat. No.01TH8560), 79-84. https://doi.org/10.1109/ISATP.2001.928970

Shamsuzzoha, A., Helo, P., \& Sandhu, M. (2016). Green virtual business network for managing and reusing waste between partner organizations. Working Conference on Virtual Enterprises, 639-651. Springer.

Suginouchi, S., Kokuryo, D., \& Kaihara, T. (2017). Value Co-creative Manufacturing System for Mass Customization: Concept of Smart Factory and Operation Method Using Autonomous Negotiation Mechanism. Procedia CIRP, 63, 727-732.

https://doi.org/https://doi.org/10.1016/j.procir.20 17.03.313

Tewari, R. (2005). CHAPTER 5 - Environmental Engineering Solutions (F. J. Agardy \& N. L. B. T.-E. S. Nemerow, https://doi.org/https://doi.org/10.1016/B978012088441-4/50006-X

The World Bank, \& OECD. (2018). Manufacturing, value added ( $\%$ of GDP). Retrieved from https://data.worldbank.org/indicator/NV.IND.M ANF.ZS?

Weichhart, G., Molina, A., Chen, D., Whitman, L. E., \& Vernadat, F. (2016). Challenges and current developments for Sensing, Smart and Sustainable Enterprise Systems. Computers in Industry, 79, 34-46. https://doi.org/https://doi.org/10.1016/j.compind. 2015.07.002

\section{Statements and Declarations}

Funding. GRANT P16.700099.001/02-04

Conflicts of interest. Not applicable

Availability of data and material. Yes

Code Availability. Not applicable

Ethics approval: Not applicable.

Consent to participate. All authors consent to participate in this research.

Consent for publication. All authors have read and approved the final manuscript. The selection of this journal is suitable for all those interested.

Author's contribution. IPPMD reference framework. Two case studies are provided to support the realization of the work. All authors contributed to the study design. The structure and design of the article was guided by Arturo Molina and Jorge Medina. The literature review was carried out mostly by José Antonio Ramírez. The union of concepts, development 
of the methodology, application in the different case studies and writing of the draft versions of the manuscripts was carried out by Daniel Cortés. All authors read and approved the final manuscript. 